\title{
Nowcasting and Forecasting Economic Growth in the Euro Area using Principal Components
}

Irma Hindrayanto'

Siem Jan Koopman²

Jasper de Winter

I De Nederlandsche Bank, the Netherlands;

2 Faculty of Economics and Business Administration, VU University Amsterdam, and Tinbergen Institute, the Netherlands. 
Tinbergen Institute is the graduate school and research institute in economics of Erasmus University Rotterdam, the University of Amsterdam and VU University Amsterdam.

More TI discussion papers can be downloaded at http://www.tinbergen.nl

Tinbergen Institute has two locations:

Tinbergen Institute Amsterdam

Gustav Mahlerplein 117

1082 MS Amsterdam

The Netherlands

Tel.: +31(0)205251600

Tinbergen Institute Rotterdam

Burg. Oudlaan 50

3062 PA Rotterdam

The Netherlands

Tel.: +31(0)10 4088900

Fax: $+31(0) 104089031$

Duisenberg school of finance is a collaboration of the Dutch financial sector and universities, with the ambition to support innovative research and offer top quality academic education in core areas of finance.

DSF research papers can be downloaded at: http://www.dsf.nl/

Duisenberg school of finance

Gustav Mahlerplein 117

1082 MS Amsterdam

The Netherlands

Tel.: +31(0)20 5258579 


\title{
Nowcasting and forecasting economic growth in the euro area using principal components
}

\author{
Irma Hindrayanto*, Siem Jan Koopman ${ }^{\dagger}$ and Jasper de Winter ${ }^{\ddagger}$ \\ * De Nederlandsche Bank, The Netherlands \\ †VU University Amsterdam, The Netherlands \& CREATES Aarhus University, Denmark \\ a.i.w.hindrayanto@dnb.nl s.j.koopman@vu.nl j.m.de.winter@dnb.nl
}

August 20, 2014

\begin{abstract}
Many empirical studies have shown that factor models produce relatively accurate forecasts compared to alternative short-term forecasting models. These empirical findings have been established for different macroeconomic data sets and different forecast horizons. However, various specifications of the factor model exist and it is a topic of debate which specification is most effective in its forecasting performance. Furthermore, the forecast performances of the different specifications during the recent financial crisis are also not well documented. In this study we investigate these two issues in depth. We empirically verify the forecast performance of three factor model approaches and report our findings in an extended empirical out-ofsample forecasting competition for quarterly growth of gross domestic product in the euro area and its five largest countries over the period 1992-2012. We also introduce two extensions of existing factor models to make them more suitable for real-time forecasting. We show that the factor models have been able to systematically beat the benchmark autoregressive model, both before as well as during the financial crisis. The recently proposed collapsed dynamic factor model shows the highest forecast accuracy for the euro area and the majority of countries that we have analyzed. The forecast precision improvements against the benchmark model can range up to $77 \%$ in mean square error reduction, depending on the country and forecast horizon.
\end{abstract}

Keywords: Factor models, Principal component analysis, Forecasting, Kalman filter, State space method, Publication lag, Mixed frequency.

\footnotetext{
* Irma Hindrayanto, Economics and Research Division, De Nederlandsche Bank, The Netherlands.

${ }^{\dagger}$ Siem Jan Koopman, Department of Econometrics, VU University Amsterdam and Tinbergen Institute, The Netherlands; CREATES Aarhus University, Denmark.

${ }^{\ddagger}$ Jasper de Winter, Economics and Research Division, De Nederlandsche Bank, The Netherlands.
} 


\section{Introduction}

It is widely acknowledged that forecasting macroeconomic time series is of key importance for economic policy makers but also for the general public. Reliable short-term forecasts are especially in high demand when the economic environment is uncertain. Many different methodologies exist for this purpose, ranging from basic time series models to sophisticated dynamic factor models. Over the last decade the latter have become a popular tool for short-term forecasting amongst practitioners and econometricians. This is due to their good forecast performance as shown in amongst others Stock and Watson (2002) and Giannone et al. (2008) for the United States, Rünstler et al. (2009) and Angelini et al. (2011) for the euro area and Schumacher and Breitung (2008) for Germany. Despite the increasing attention for factor models, the appropriate specification of a factor model remains a topic of debate. One of the issues is how to determine the optimal number of factors in the model; see, for example, Bai and Ng $(2002,2007)$. Another issue of debate is the determination of the optimal size of the database for the extraction of the factors; see, for example, the discussions in Caggiano et al. (2011) and den Reijer (2013). A related issue that has attracted relatively little attention in the literature is the gain in forecast accuracy resulting from including autoregressive terms of the target variable in the model specification, i.e. including one or more lags of the targeted variable in the forecast equation. However, recent studies indicate this might be a promising extension in terms of forecast accuracy. Clements and Galvão (2008), Kuzin et al. (2011) and Jansen et al. (2012) find that the inclusion of an autoregressive term significantly improves the forecast accuracy for a range of different models. It is an empirical question whether this conclusion also holds for factor models.

Our study compares the short-term forecast performance of different factor models for quarterly gross domestic product (GDP) growth for the euro area and its five largest countries before and during the financial crisis. We present a concise discussion of the literature on short-term forecasting using factor models and consider several recent developments. The earliest contributions on dynamic factor analysis have been recently reviewed by Stock and Watson (2006), Breitung and Eickmeier (2006) and Bai and Ng (2008). We concentrate on three factor models: the canonical factor model of Stock and Watson (2002) who have initiated the current literature on factor models, the widely used dynamic factor model of Bańbura and Rünstler (2011) and the recently proposed collapsed dynamic factor model of Bräuning and Koopman (2014). The two dynamic factor models are siblings of the canonical factor model of Stock and Watson (2002) as the models are all built on the idea of using principal components to summarize the information in a large set of monthly indicators. However, in contrast to Stock and Watson (2002), both dynamic factor models analyze the target and the principal components simultaneously in a multivariate unobserved component time series model. This model setup allows for panels with mixed-frequencies and for the efficient handling of monthly series with different publication delays and different starting dates. These differences lead to a data matrix of monthly time series with so-called "jagged" or "ragged" edges at the beginning and end of the sample.

The econometric foundation of the Bańbura and Rünstler (2011) model is described in Doz et al. (2011) who propose a two-step estimation method. In the first step, the principal components are computed and its dynamic properties are estimated by means of a vector autoregressive model. In the second step, the factor estimates and forecasts are obtained from the Kalman filter and smoother. Doz et al. (2011) provide the asymptotic properties of the Kalman filter and smoother estimates and apply the model to forecast quarterly GDP growth with monthly variables containing jagged edges at the beginning and the end of 
the sample. Bańbura and Rünstler (2011) develop this approach further for quarterly GDP growth and show how the contributions of individual variables in the factor model forecasts can be measured using the methods of Koopman and Harvey (2003).

The model of Bräuning and Koopman (2014) differs from Bańbura and Rünstler (2011) mainly as follows. Firstly the former model adopts a low-dimensional unobserved components model for the target variable and a set of principal components from which the dynamic factors are extracted. The unknown parameters in this more parsimonious model are jointly estimated by using maximum likelihood for which the loglikelihood function is evaluated using the Kalman filter and smoother. The resulting model setup captures the cross-sectional and dynamic time series information jointly in a transparent and optimal way. Secondly, in the Bräuning and Koopman (2014) model, the idiosyncratic part for the target vector series is modeled explicitly and estimated jointly with the dynamic factors. This mitigates the problem that the estimated factors in a large macroeconomic panel are not considering information from the forecasting target.

The main contributions of this paper are threefold. Firstly, we extend the approach of Bräuning and Koopman (2014) by proposing a more efficient way of handling the jagged edges in the collapsed dynamic factor model. We propose a three-step method. In the first step we analyze each univariate time series by an unobserved components model to extract the main signal for interpolating (or extrapolating) the jagged edges, in the second step we extract the principal components and in the third step we estimate all model parameters simultaneously. The efficient handling of the jagged edges significantly improves the forecast accuracy. Secondly, we extend the model of Bańbura and Rünstler (2011) by including autoregressive terms in the model, putting it on more equal footing with the models of Stock and Watson (2002) and Bräuning and Koopman (2014). This modification improves the forecast accuracy of the Bańbura and Rünstler (2011) model. Thirdly, we verify rigorously the forecast accuracy of the three factor models. We present a systematic comparison of the factor models for the euro area and its five largest countries (Germany, France, Italy, Spain and the Netherlands) utilizing the same information set across countries and the euro area. We show that the factor models are able to systematically beat the benchmark autoregressive model. The good performance of the factor models is not limited to the pre-crisis period, but the models also outperform the benchmark model during the financial crisis. In this period, factor models have improved the forecast accuracy of the benchmark model by up to $77 \%$, in terms of mean square error, depending on factor model, country and forecast horizon. Overall, the performance of the collapsed dynamic factor has been most successful.

The remainder of the paper is organized as follows. Section 2 gives an overview of the factor models of Stock and Watson (2002), Bańbura and Rünstler (2011), and Bräuning and Koopman (2014) and introduces the modifications we propose for the Bańbura and Rünstler (2011) and Bräuning and Koopman (2014) models. Section 3 provides details on the construction of the database, the forecast setup and specification details such as the number of common factors and lags. Section 4 discusses the empirical results of our forecasting study. We summarize our findings in Section 5.

\section{Factor models using principal components}

We consider three factor models: the autoregressive model with principal components as covariates and proposed by Stock and Watson (2002); the high-dimensional dynamic factor model of Bańbura and Rünstler (2011); and the (collapsed) low-dimensional dynamic factor 
model of Bräuning and Koopman (2014). We focus on forecasting the quarterly GDP growth rate (quarter on quarter), denoted as $y_{t_{q}}^{Q}$, where $t_{q}=1, \ldots, T_{q}$ is the quarterly time index. We follow the statistical convention by having the quarterly GDP growth rate at the monthly frequency by setting $y_{t}^{M}$ equal to the growth rate $\left(y_{t_{q}}^{Q}\right)$ in the third month of each quarter $\left(t=3 t_{q}\right)$ and to a missing value otherwise, where $t=1, \ldots, T$ is the monthly time index. The time dimensional relation is $T_{q}=\lfloor T / 3\rfloor$. We define $y_{t}$ as the latent monthly GDP growth rate, i.e. the 3 -month growth rate with respect to the corresponding month of the previous quarter. Furthermore, we define $y_{t}^{*}$ as the mean-adjusted series of $y_{t}$, that is $y_{t}^{*}=y_{t}-\mu$ where $\mu$ is the in-sample mean of $y_{t_{q}}^{Q}$.

The factor models that we describe in the remainder of this section all use principal component analysis to extract $r$ monthly common factors, $F_{t}$, from a $N$-dimensional standardized stationary monthly time series of candidate predictors, $X_{t}$, for $t=1, \ldots, T$. We denote the matrix of eigenvalues (or factor loadings) as $\Lambda$. The vector $F_{t_{q}}^{Q}$ contains the $q$ quarterly factors that we calculate by taking the three-month averages of $F_{t}$.

\subsection{Stock and Watson: autoregression with principal components}

The Stock and Watson (2002) model is designed for the forecasting of a single time series with length $T$, using a large number $N$ of candidate predictor series, where typically $N>>T$. The high-dimensional problem is reduced to an univariate autoregressive model for the key economic time series of interest with the inclusion of a small number of principal components that are used as predictors. The autoregressive model is for the target variable with a specific forecast horizon. More specifically, the variable to forecast is $y_{t_{q}+h}^{Q}$ using the data $\left(F_{t_{q}}^{Q}, y_{t_{q}}^{Q}\right)$ and the model as given by

$$
y_{t_{q}+h}^{Q}=\alpha_{h}+\sum_{j=1}^{p} \beta_{h, j} F_{t_{q}-j}^{Q}+\sum_{k=1}^{m} \gamma_{h, k} y_{t_{q}-k}^{Q}+\varepsilon_{t_{q}+h}^{Q}, \quad t_{q}=1, \ldots, T_{q},
$$

where $h$ is the forecast horizon, $\alpha_{h}$ is the constant term, $\beta_{h}(L)$ and $\gamma_{h}(L)$ are finite-order autoregressive lag polynomials $\beta_{h, j}$ and $\gamma_{h, k}$ are regression coefficients, for $j=1, \ldots, p$ and $k=1, \ldots, m$, and $\varepsilon_{t_{q}+h}^{Q}$ is the disturbance. The lag dimensions $p$ and $m$ are set a-priori. All parameters are indicated by forecast horizon $h$. Although the model remains the same, it is assumed that for each horizon $h$ the coefficients of the model can be different. Hence in the Stock and Watson procedure the model coefficients are re-estimated for each forecast horizon $h$ while we hold the set of explanatory variables fixed. The principal components $F_{t}$ are obtained from a balanced sub-sample of $X_{t}$ 's which is obtained by discarding the rows that have missing values at the end of the estimation period. This typically only involves removing the last few rows that are not complete due to publication delays. The missing values at the beginning of the sample are dealt with by using the Expectation Maximization (EM) algorithm described in Stock and Watson (2002).

Forecasting is then carried out in a two-step procedure: first, the factors (or principal components) are obtained from the set of candidate predictors; second, the parameters of the autoregressive model are estimated by the method of ordinary least squares (OLS) from which the forecasts can be generated. In this way, any forecast, from $y_{T_{q}+1}^{Q}$ to $y_{T_{q}+h^{*}}^{Q}$, for some $h^{*}>1$, can be computed easily but the two-step procedure must be repeated for each forecast horizon. Typically, the lag dimensions $p$ and $q$ are kept fixed for each forecast horizon and are often both set equal to two. 


\subsection{Bańbura and Rünstler: high-dimensional dynamic factor model}

The Bańbura and Rünstler (2011) model is based on the dynamic factor model of Giannone et al. (2008) that is given by

$$
\begin{aligned}
X_{t} & =\Lambda f_{t}+u_{t}, & u_{t} & \sim \operatorname{NIID}\left(0, \Sigma_{u}\right), \\
f_{t} & =\sum_{j=1}^{p} \Phi_{j} f_{t-j}+\zeta_{t}, & \zeta_{t} & \sim \operatorname{NIID}\left(0, \Sigma_{\zeta}\right),
\end{aligned}
$$

where $\Lambda$ is the loading matrix, $f_{t}$ is a $q \times 1$ vector of latent dynamic factors, $u_{t}$ is a normally, identically and independently distribited (NIID) disturbance with mean zero and variance matrix $\Sigma_{u}, \Phi_{j}$ is the autoregressive coefficient matrix, for $j=1, \ldots, p$, and $\zeta_{t}$ is a NIID disturbance with mean zero and variance matrix $\Sigma_{\zeta}$, and the two disturbance series $u_{t}$ and $\zeta_{t}$ are mutually independent. The variance matrix $\Sigma_{u}$ is typically assumed to be diagonal. The latent dynamic stochastic process for $f_{t}$ is explicitly modelled as a stationary vector autoregressive process with lag dimension $p$. The time index $t$ refers to months.

We have presented the dynamic factor model in state space; it allows for the efficient handling of "jagged edges", the treatment of missing values and the computation of the forecasts via the Kalman filter and smoother. Bańbura and Rünstler (2011) argue that exploiting the dynamics of the estimated latent factors directly can be beneficial in improving the forecasting accuracy. However, they recommend that factors should not be very noisy. To enforce some smoothness in the factors $f_{t}$, the rank of matrix $\Sigma_{\zeta}$ can be reduced to $r<q$. We effectively obtain $r$ stochastic factors and $q-r$ static factors. The rank $r$ can be determined on the basis of in-sample measures such as the likelihood function or outof-sample measures such as the mean squared forecast error; see also the discussions in Bai and $\mathrm{Ng}(2002)$. We consider all possible values $r=1, \ldots, q-1$ for a reduced rank variance matrix $\Sigma_{\zeta}$ and base our forecasts on the average of the $q-1$ forecasts resulting from the different models with a reduced rank variance matrix $\Sigma_{\zeta}$.

The values for the unknown parameter matrices $\Lambda, \Sigma_{u}, \Phi_{1}, \ldots, \Phi_{p}$, and $\Sigma_{\zeta}$ are determined using the $q$ principal components $F_{t}$ 's as outlined by Giannone et al. (2008). The principal components $F_{t}$ are based on the eigendecompostion of the sample variance matrix of the data matrix $\left[X_{1}, \ldots X_{T}\right]^{\prime}$, denoted by the $N \times N$ positive definite matrix $S_{X}$. The columns of the $N \times q$ loading matrix $\Lambda$ is set equal to the $q$ eigenvectors associated with the $q$ largest eigenvalues of $S_{X}$. The variance matrix $\Sigma_{u}$ is set to a diagonal matrix with the $i$ th diagonal element equal to the $(i, i)$ element of the sample variance matrix of the data matrix $\left[\left(X_{1}-\Lambda F_{1}\right), \ldots,\left(X_{T}-\Lambda F_{T}\right)\right]^{\prime}$. The matrix parameters in (3) are set equal to their OLS estimates applied to vector autoregressive model equation $(3)$ where $f_{t}$ is replaced by $F_{t}$, for $t=1, \ldots, T$.

The incorporation of the quarterly target series $y_{t_{q}}^{Q}$ in the monthly state space model (2) - (3) is required for its forecasting. Here we follow Mariano and Murasawa (2003) in the forecasting of mean-adjusted quarterly GDP growth in a mixed-frequency modelling framework. We introduce the univariate mean-adjusted latent monthly variable $y_{t}^{*}$ which is modelled as

$$
y_{t}^{*}=\beta^{\prime} f_{t}+\varepsilon_{t}, \quad \varepsilon_{t} \sim \operatorname{NIID}\left(0, \sigma_{\varepsilon}^{2}\right), \quad t=1, \ldots, T,
$$

where $\beta$ is a $q \times 1$ vector of coefficients and $\varepsilon_{t}$ is a NIID disturbance and mutually independent of $u_{t}$ and $\zeta_{t}$. The link with $y_{t}^{*}$ and the observed quarterly GDP growth rate $y_{t_{q}}^{Q}$ is established as follows. We create a monthly time series $y_{t}^{M}$ of missing values except at time $t=3 t_{q}$ 
where it is set equal to $y_{t_{q}}^{Q}$. We further introduce a recursive latent cumulator variable $y_{t}^{* C}$ that is generated by

$$
y_{t+1}^{* C}=\delta_{t} y_{t}^{* C}+\frac{1}{3} y_{t+1}^{*}, \quad \delta_{t}= \begin{cases}0, & t=3 t_{q}, \\ 1, & \text { otherwise }\end{cases}
$$

for $t=1, \ldots, T$ and $t_{q}=1, \ldots, T_{q}$, with initialization of the cumulator variable as $y_{1}^{* C}=\frac{1}{3} y_{1}^{*}$. It is implied that $y_{t}^{* C}$, when $t=3 t_{q}$, equals the average of the latent monthly series $y_{t}^{*}$ within quarter $t_{q}$ and hence it is equal to the observed $y_{t_{q}}^{Q} \equiv y_{t}^{M}=y_{t}^{* C}+\mu$ where $\mu$ is the in-sample mean of $y_{t_{q}}^{Q}$. The remaining values for $y_{t}^{*}$ can be estimated via the Kalman filter and smoother.

The values for the unknown parameters $\beta$ and $\sigma_{\varepsilon}^{2}$ are determined by OLS applied to the regression model

$$
y_{t_{q}}^{Q}=\beta^{\prime} F_{t_{q}}^{Q}+e_{t_{q}}^{Q}, \quad e_{t_{q}}^{Q} \sim \operatorname{NIID}\left(0, \sigma_{e}^{2}\right) .
$$

The value for $\sigma_{\varepsilon}^{2}$ is obtained via the relation $\sigma_{\varepsilon}^{2}=\sigma_{e}^{2} / 3$.

The nowcasting and forecasting of quarterly GDP growth is based on the Kalman filter and smoother applied to the state space model as given by the observation equation

$$
\left(\begin{array}{c}
X_{t} \\
y_{t}^{M}
\end{array}\right)=\left(\begin{array}{c}
0 \\
\mu
\end{array}\right)+\left[\begin{array}{cccc}
\Lambda & 0 & 0 & 0 \\
0 & 0 & 0 & 1
\end{array}\right]\left(\begin{array}{c}
f_{t} \\
f_{t-1} \\
y_{t}^{*} \\
y_{t}^{* C}
\end{array}\right)+\left(\begin{array}{c}
u_{t} \\
0
\end{array}\right)
$$

where $\mu$ is the sample average of the observed quarterly GDP growth rates $y_{t_{q}}^{Q}$, and hence of $y_{t}^{M}$, and the transition equation is given by

$$
\left[\begin{array}{cccc}
I_{r} & 0 & 0 & 0 \\
0 & I_{r} & 0 & 0 \\
-\beta^{\prime} & 0 & 1 & 0 \\
0 & 0 & -1 / 3 & 1
\end{array}\right]\left(\begin{array}{c}
f_{t+1} \\
f_{t} \\
y_{t+1}^{*} \\
y_{t+1}^{* C}
\end{array}\right)=\left[\begin{array}{cccc}
\Phi_{1} & \Phi_{2} & 0 & 0 \\
I_{r} & 0 & 0 & 0 \\
0 & 0 & 0 & 0 \\
0 & 0 & 0 & \delta_{t}
\end{array}\right]\left(\begin{array}{c}
f_{t} \\
f_{t-1} \\
y_{t}^{*} \\
y_{t}^{* C}
\end{array}\right)+\left(\begin{array}{c}
\zeta_{t} \\
0 \\
\varepsilon_{t+1} \\
0
\end{array}\right),
$$

for $t=1, \ldots, T$. All variables are introduced in the equations (2)-(5). This state space representation is based on $q=1$ and $p=2$; it is straightforward to amend it for other values of $q$ and $p$. We notice that the time series $y_{t}^{M}$ contains many missing values. The jagged edges in data matrix $\left(X_{1}, \ldots, X_{t}\right)$ can also be regarded as a missing value problem. The treatment of missing values, the computation of forecasts and the estimation of $f_{t}$ and $y_{t}^{*}$ using the Kalman filter and smoother are discussed in detail in Durbin and Koopman (2012). The transition equation (7) is non-standard given the pre-multiplication of the state vector on the left-handside of the equation; a minor modification provides the standard updating equation but is somewhat less intuitive.

\subsection{Bańbura and Rünstler: an extension}

In earlier empirical studies, for example in Jansen et al. (2012), it is shown that adding autoregressive terms in the forecast equation can significantly improve forecast accuracy for GDP growth. The inclusion of autoregressive terms, or lagged values of $y_{t}$, in (4) can simply be achieved by considering

$$
y_{t}^{*}=\rho_{1} y_{t-1}^{*}+\rho_{2} y_{t-2}^{*}+\beta^{\prime} f_{t}+\varepsilon_{t}, \quad \varepsilon_{t} \sim N\left(0, \sigma_{\varepsilon}^{2}\right),
$$


for $t=1, \ldots, T$, where $\rho_{1}$ and $\rho_{2}$ are the additional coefficients of the autoregressive process. We then adjust the state space form accordingly. To illustrate, the observation equation for $r=1$ and $p=2$ is defined as:

$$
\left(\begin{array}{c}
X_{t} \\
y_{t}^{M}
\end{array}\right)=\left(\begin{array}{c}
0 \\
\mu
\end{array}\right)+\left[\begin{array}{ccccc}
\Lambda & 0 & 0 & 0 & 0 \\
0 & 0 & 0 & 0 & 1
\end{array}\right]\left(\begin{array}{c}
f_{t} \\
f_{t-1} \\
y_{t}^{*} \\
y_{t-1}^{*} \\
y_{t}^{* C}
\end{array}\right)+\left(\begin{array}{c}
e_{t} \\
0
\end{array}\right),
$$

where $\mu$ is the in-sample mean of $y_{t_{q}}^{Q}$. The transition equation is given by:

$$
\left[\begin{array}{ccccc}
I_{r} & 0 & 0 & 0 & 0 \\
0 & I_{r} & 0 & 0 & 0 \\
-\beta^{\prime} & 0 & 1 & 0 & 0 \\
0 & 0 & 0 & 1 & 0 \\
0 & 0 & -1 / 3 & 0 & 1
\end{array}\right]\left(\begin{array}{c}
f_{t+1} \\
f_{t} \\
y_{t+1}^{*} \\
y_{t}^{*} \\
y_{t+1}^{* C}
\end{array}\right)=\left[\begin{array}{ccccc}
\Phi_{1} & \Phi_{2} & 0 & 0 & 0 \\
I_{r} & 0 & 0 & 0 & 0 \\
0 & 0 & \rho_{1} & \rho_{2} & 0 \\
0 & 0 & 1 & 0 & 0 \\
0 & 0 & 0 & 0 & \delta_{t}
\end{array}\right]\left(\begin{array}{c}
f_{t} \\
f_{t-1} \\
y_{t}^{*} \\
y_{t-1}^{*} \\
y_{t}^{* C}
\end{array}\right)+\left(\begin{array}{c}
\zeta_{t} \\
0 \\
\varepsilon_{t+1} \\
0 \\
0
\end{array}\right) .
$$

We obtain values for the parameters $\rho_{1}, \rho_{2}, \beta$ and $\sigma_{\varepsilon}^{2}$ from their OLS estimates in the regression model

$$
\widetilde{y}_{t}^{* M}=\rho_{1} \widetilde{y}_{t-1}^{* M}+\rho_{2} \widetilde{y}_{t-2}^{* M}+\beta^{\prime} F_{t}+e_{t}^{M}, \quad e_{t}^{M} \sim \operatorname{NIID}\left(0, \sigma_{\varepsilon}^{2}\right),
$$

for $t=1, \ldots, T$ and where $\widetilde{y}_{t}^{* M}$ is the monthly time series of the linearly interpolated meanadjusted quarterly series of $y_{t_{q}}^{Q}$, that is $\widetilde{y}_{t}^{* M}=y_{s_{t}}^{* Q} / 3+\left(t-3 s_{t}\right)\left(y_{s_{t}+1}^{* Q}-y_{s_{t}}^{* Q}\right) / 3$ for $t=1, \ldots, T$ and $s_{t}=\lfloor t / 3\rfloor$, where $y_{t_{q}}^{* Q}=y_{t_{q}}^{Q}-\mu$ and with $y_{0}^{* Q}=y_{1}^{* Q}$.

\subsection{Bräuning and Koopman: collapsed dynamic factor model}

The collapsed dynamic factor model of Bräuning and Koopman (2014) is effectively a lowdimensional multivariate unobserved components time series model where the target series and a set of $q$ principal components are treated jointly as dependent variables. The number of unknown parameters to be estimated is relatively small. Maximum likelihood estimation is carried out via the numerical maximization of the loglikelihood function that is evaluated by the Kalman filter.

The model of Bräuning and Koopman (2014) is based on the dynamic factor model (2) that is extended with the target series of quarterly GDP growth in a specific way. To accommodate the monthly and quarterly series, we formulate the extension of the model in terms of the unobservable series $y_{t}^{*}$ and we obtain

$$
\left(\begin{array}{l}
X_{t} \\
y_{t}^{*}
\end{array}\right)=\left[\begin{array}{ll}
\Lambda & 0 \\
\Gamma & 1
\end{array}\right]\left(\begin{array}{c}
f_{t} \\
\psi_{t}
\end{array}\right)+\left(\begin{array}{c}
u_{t} \\
0
\end{array}\right)
$$

where $\Gamma$ is a loading matrix with the coefficients of the dynamic factors for the monthly unobserved series $y_{t}^{*}, \psi_{t}$ is a univariate latent dynamic process for the target series and the definitions for the other matrices and variables remain as above. The dynamic factors $f_{t}$ are modelled as the vector autoregressive process (3) while the unobserved component $\psi_{t}$ for the target series can also be modelled as an autoregressive process, for example,

$$
\psi_{t+1}=\phi_{1} \psi_{t}+\phi_{2} \psi_{t-1}+\eta_{t}, \quad \eta_{t} \sim \operatorname{NIID}\left(0, \sigma_{\eta}^{2}\right),
$$

where $\phi_{1}$ and $\phi_{2}$ are autoregressive coefficients and $\eta_{t}$ is a NIID disturbance and mutually independent of other disturbances in the model. The monthly series $y_{t}^{*}$ is linked with the 
(partially) observed monthly series $y_{t}^{M}$ in the relation $y_{t}^{M}=\mu+y_{t}^{* C}$ when $t=3 t_{q}$ and where $y_{t}^{* C}$ is constructed as in $(5)$.

The collapsed dynamic factor model is based on the insight that the principal component $F_{t}$ is a linear combination of $X_{t}$, that is $F_{t}=A X_{t}$ for $t=1, \ldots, T$ and for a matrix $A$ with property $A \Lambda=I$. Pre-multiplying (11) by matrix

$$
\left[\begin{array}{ll}
A & 0 \\
0 & 1
\end{array}\right]
$$

we obtain

$$
\left(\begin{array}{c}
F_{t} \\
y_{t}^{*}
\end{array}\right)=\left[\begin{array}{ll}
I & 0 \\
\Gamma & 1
\end{array}\right]\left(\begin{array}{c}
f_{t} \\
\psi_{t}
\end{array}\right)+\left(\begin{array}{c}
v_{t} \\
0
\end{array}\right),
$$

where $v_{t}=A u_{t}$, for $t=1, \ldots, T$.

Next we provide the state space model for the observed series of principal components $F_{t}$ and of quarterly GDP growth $y_{t}^{M}$. Our specification is based on the collapsed dynamic factor model with (13), (12) and (3), for $p=2$. The state space form consists of the observation equation

$$
\left(\begin{array}{c}
F_{t} \\
y_{t}^{M}
\end{array}\right)=\left(\begin{array}{c}
0 \\
\mu
\end{array}\right)+\left[\begin{array}{llllll}
I & 0 & 0 & 0 & 0 & 0 \\
0 & 0 & 0 & 0 & 0 & 1
\end{array}\right]\left(\begin{array}{c}
f_{t} \\
f_{t-1} \\
\psi_{t} \\
\psi_{t-1} \\
y_{t}^{*} \\
y_{t}^{* C}
\end{array}\right)+\left(\begin{array}{c}
v_{t} \\
\varepsilon_{t}
\end{array}\right)
$$

and the transition equation

$$
\left[\begin{array}{cccccc}
I & 0 & 0 & 0 & 0 & 0 \\
0 & I & 0 & 0 & 0 & 0 \\
0 & 0 & 1 & 0 & 0 & 0 \\
0 & 0 & 0 & 1 & 0 & 0 \\
-\Gamma & 0 & -1 & 0 & 1 & 0 \\
0 & 0 & 0 & 0 & -1 / 3 & 1
\end{array}\right]\left(\begin{array}{c}
f_{t+1} \\
f_{t} \\
\psi_{t+1} \\
\psi_{t} \\
y_{t+1}^{*} \\
y_{t+1}^{* C}
\end{array}\right)=\left[\begin{array}{cccccc}
\Phi_{1} & \Phi_{2} & 0 & 0 & 0 & 0 \\
I & 0 & 0 & 0 & 0 & 0 \\
0 & 0 & \phi_{1} & \phi_{2} & 0 & 0 \\
0 & 0 & 1 & 0 & 0 & 0 \\
0 & 0 & 0 & 0 & 0 & 0 \\
0 & 0 & 0 & 0 & 0 & \delta_{t}
\end{array}\right]\left(\begin{array}{c}
f_{t} \\
f_{t-1} \\
\psi_{t} \\
\psi_{t-1} \\
y_{t}^{*} \\
y_{t}^{* C}
\end{array}\right)+\left(\begin{array}{c}
\zeta_{t} \\
0 \\
\eta_{t} \\
0 \\
0 \\
0
\end{array}\right),
$$

for $t=1, \ldots, T$. The unknown parameters $\Phi_{1}, \Phi_{2}, \Gamma, \phi_{1}, \phi_{2}, \Sigma_{\zeta}, \sigma_{\eta}^{2}$ and $\sigma_{\varepsilon}^{2}$ are estimated by maximum likelihood. The number of unknown parameters is $4(q+1)$, that is 8 and 12 for $q=1$ and $q=2$, respectively.

In contrast to the approach of Bańbura and Rünstler (2011), the collapsed dynamic factor model requires a pre-analysis to treat the jagged edges in the data matrix $\left(X_{1}, \ldots, X_{T}\right)$ because we do not model $X_{t}$ but its principal component $F_{t}$ instead. We may adopt the EM method of Stock and Watson (2002) for the purpose of computing the $F_{t}$ 's. However, it has turned out that it is more effective to consider a simple univariate model for each variable in $X_{t}$ and use the model to interpolate and extrapolate its missing values using the Kalman filter and smoother. In particular, for the $i$ th time series $X_{i t}$ in $X_{t}$, we consider the stationary decomposition model

$$
X_{i t}=\theta_{i t}+\kappa_{i t}, \quad t=1, \ldots, T
$$

where $\theta_{i t}$ is an autoregressive process and $\kappa_{i t}$ is a NIID disturbance (mutually independent of any other disturbance series), for $i=1, \ldots, N$. We typically let $\theta_{i t}$ be an autoregressive 
process with two lags. We further notice that each observed time series $X_{i t}$ is standardized and hence has a sample mean of zero and a sample variance of unity. After the estimation of the unknown parameters, the Kalman filter and smoother replaces the missing entries by their corresponding estimates. In this way we obtain a balanced data set $\left(X_{1}, \ldots, X_{T}\right)$ and the principal components can be constructed in a standard way.

The use of a stationary autoregressive process for $\theta_{i t}$ ensures that the balanced variable return to their long term mean of zero when a long sequence of entries is missing. Figure 1 presents two examples in the data set of our empirical illustration in Section 4 The first variable only contains missings at the beginning of the sample while the second variable contains missings only at the end of the sample.
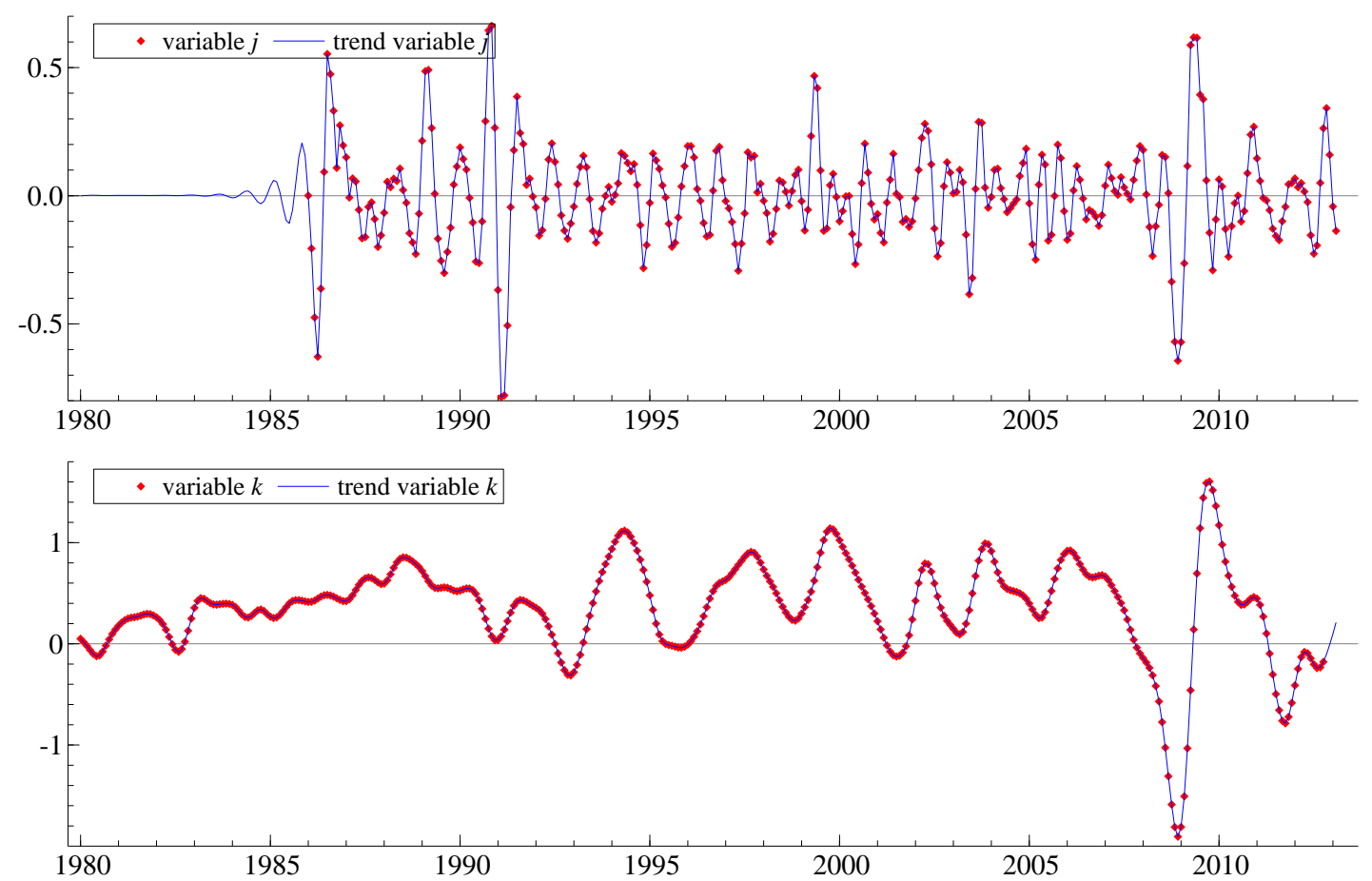

Figure 1: The treatment of missing values for two economic variables in our empirical illustration. The first variable is unbalanced and has missings at the beginning of the series. The second variable has only a few missings at the end of the series.

\section{Data, forecast design and specification issues}

\subsection{Dataset}

Our monthly data set of predictors consists of 52 monthly time series, using harmonized definitions across countries. The selected variables fall into four predefined categories: production \& sales, prices, monetary \& financial indicators and surveys. Table IV in the Appendix provides an overview of all variables, the applied transformations and the starting date of the monthly series for each country in our sample. Monthly data are typically available after their adjustments for seasonal and calendar effects. When necessary, the time series are seasonally adjusted by the US Census X12-ARIMA-program at their default settings. All monthly series are made stationary by differencing or log-differencing (in case of trending 
data, such as industrial production, retail sales and monetary aggregates). Thereafter, the variables are standardized by subtracting the mean and dividing them by their standard deviation. This standardization is necessary to avoid overweighting of large variance series in the extraction of common factors.

Our primary source of all data is the statistical data warehouse of the European Central Bank (ECB) 1 The world trade series are taken from the the world trade monitor data set of the Netherlands Bureau of Policy Analysis (CPB) ${ }^{2}$ Since their world trade series only start in 1991 we backdated the series using the world trade data from data sets provided by the International Monetary Fund (IMF). Time series on industrial production for the United States are downloaded from the Board of Governors of the Federal Reserve System 3 The Commodity prices and most financial market indicators are taken from Thomson Reuters Datastream. Survey data are taken from the European Commission ${ }^{4}$ and the Purchasing Managers Indices for the United States and United Kingdom are from Markit services 5

The quarterly GDP series for Italy, Spain and the Netherlands start in the first quarter of 1981.I, 2000.I and 1988.I, respectively. To backdate the GDP series to 1980.I we use the "release data and revisions" database of the Organisation for Economic Co-operation and Development (OECD) that contains historical GDP vintages ${ }^{6}$ The backdated GDP series were constructed by applying the quarter-on-quarter growth rates from the most recent GDP vintages of the OECD. In particular, for Italy we used the March 2013 and April 2006 vintages, for Spain the March 2013, November 2011, May 2005 and July 1999 vintages and for the Netherlands the March 2013 and July 2005 vintages. Quarterly GDP data for Germany were taken from the Deutsche Bundesbank 7 who constructed the GDP series using only GDP data for West Germany pre 1991.I and the re-unified Germany from 1991.I onwards. We constructed a synthetic GDP series for the euro area using the database underlying the ECB's Area Wide Model ${ }^{8}$ supplemented with data from the OECD database.

\subsection{Pseudo real-time design}

The forecast design aims to replicate the availability of the data at the time forecasts are made in order to mimic the real-time flow of information as closely as possible. To this end, we used a data set downloaded on March 4, 2013 and combined this with the typical data release calendar to reconstruct the available dataset on the $4^{\text {th }}$ of each month during the period January 1992 - December 2012. We construct the database such that the earliest starting date for the monthly series is January 1980, and the first quarter of 1980 for GDP. We thus employ a pseudo real-time design, which takes data publication delays into account, but ignores the possibility of data revisions for GDP and some indicators, such as industrial production. The latter implies that we might overestimate the forecast accuracy. However, large real-time datasets for the countries we considered are not (yet) available. Moreover, the effects of data revisions on the forecasts of factor might largely cancel; see, for example, Bernanke and Boivin (2003) for the United States and Schumacher and Breitung (2008) for Germany.

\footnotetext{
${ }_{1}^{1}$ http://sdw.ecb.europa.eu

2 http://www.cpb.nl/en/world-trade-monitor

3 http://www.federalreserve.gov/releases/g17/Current

4 http://ec.europa.eu/economy_finance/db_indicators/surveys/index_en.htm

5 http://www.markit.com/en/products/research-and-reports/pmis/pmi.page

6 http://stats. oecd.org/Index. aspx?querytype=view\&queryname=206

http://www.bundesbank.de/Navigation/EN/Home/home_node.html

$\varepsilon$ http://www.eabcn.org/data/awm/index.htm
} 
We estimate the parameters of all models recursively, using only the information available at the time of the forecast, see Rünstler et al. (2009); Giannone et al. (2008); Kuzin et al. (2011), among others, for a similar approach. We construct a sequence of eleven forecasts for GDP growth in a given quarter, obtained in consecutive months. Table I illustrates the timing of the forecasting exercise, taking the forecast for the third quarter of 2012 as an example. The first forecast on January 4, 2012 is referred to as the two-quarter-ahead forecast in month one. We subsequently produce a monthly forecast for the next ten months, from February until November. The last forecast is made on November 4, 2012, approximately a week and a half before the flash release of GDP in mid-November. Following the conventional terminology, forecasts refer to one or two-quarter ahead forecasts, nowcasts refer to current quarter forecasts and backcasts refer to forecasts for the preceding quarter, as long as official GDP figures are not yet available. In our example, we make two-quarter ahead forecasts from January to March, one-quarter ahead forecasts from April to June, nowcasts from July to September, and backcasts in October and November.

Table I: Timing of forecast exercise (example: forecast for 2012.III)

\begin{tabular}{|c|c|c|}
\hline Nr. & Name & Forecast made on the $4^{\text {th }}$ of \\
\hline 1 & & January \\
\hline 2 & 2Q ahead & February \\
\hline 3 & & March \\
\hline 4 & & April \\
\hline 5 & $1 \mathrm{Q}$ ahead & May \\
\hline 6 & & June \\
\hline 7 & & July \\
\hline 8 & Nowcast & August \\
\hline 9 & & September \\
\hline 10 & & October \\
\hline 11 & Backcast & November \\
\hline
\end{tabular}

\subsection{Choosing the appropriate model specification}

Many approaches exist for determining the number of factors in $F_{t}$, that is dimension $r$; see the discussion in Bai and $\mathrm{Ng}$ (2002). A standard procedure for the choice of $r$ is to apply information criteria for a range of models with different $r$. However, as noted in recent contributions, the application of information criteria might lead to inferior model specifications in terms of forecast accuracy, see Bernanke and Boivin (2003); Giannone et al. (2005); Boivin and $\mathrm{Ng}$ (2005). An alternative to using information criteria is to pool over different model specifications. In this paper we follow Kuzin et al. (2013), who conclude that taking the unweighted averaged forecast over all possible specifications of the factor models is superior to the use of information criteria or more complicated weighting schemes.

We limit our model specifications to models with two lags in the (vector) autoregressive dynamics and a maximum of four static factors. The upper bound of four was derived from the scree test of Cattell (1966) using normalized eigenvalues calculated from the set of candidate predictors. Figure 2 shows the scree plots for the euro area and its five largest countries, where the normalized eigenvalues of the largest thirty principal components are presented. The plots show that the first principal component is able to explain between 

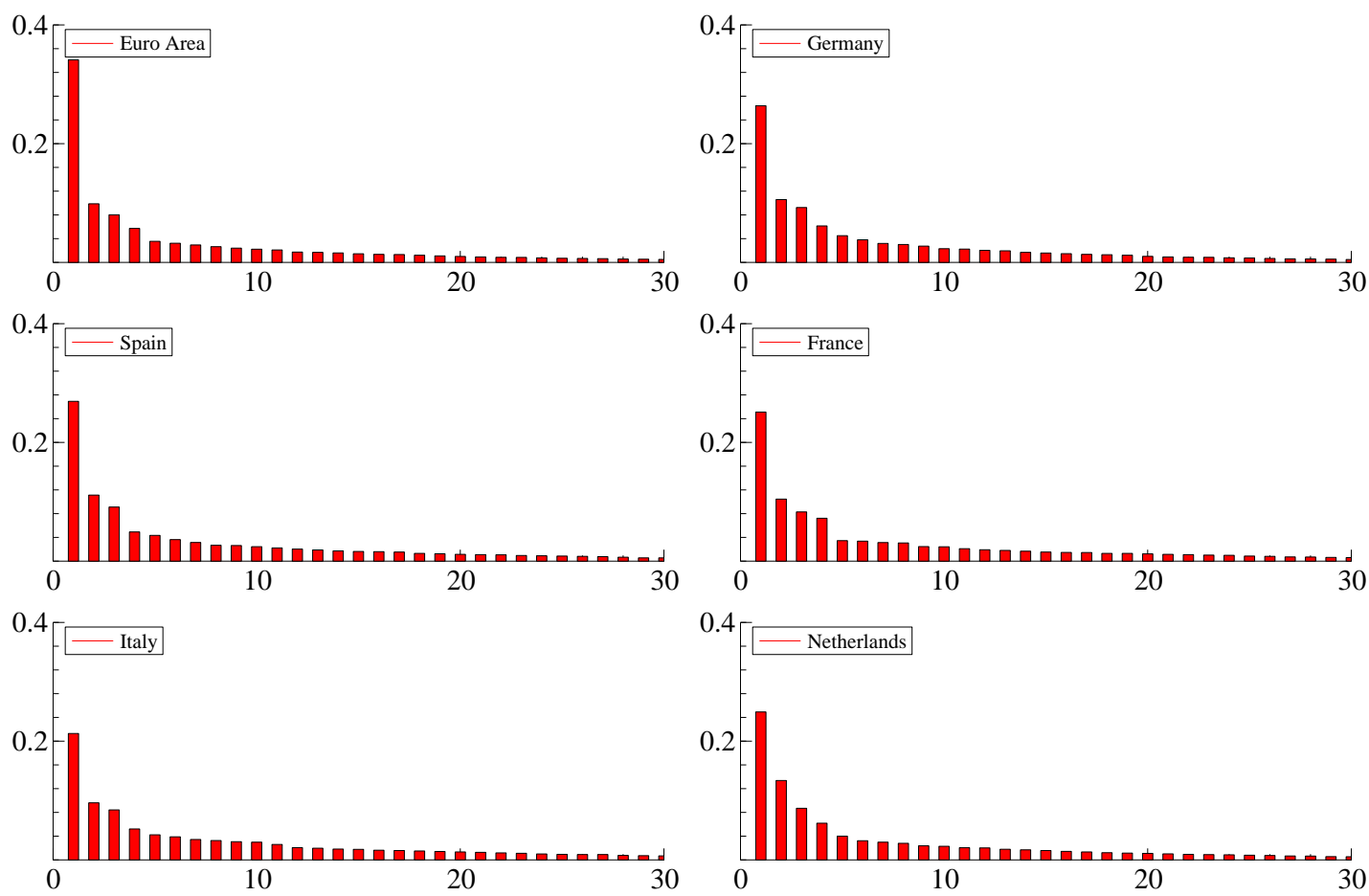

Figure 2: Scree plots of normalized eigenvalues computed from the set of candidate predictors (euro area and its five largest countries)
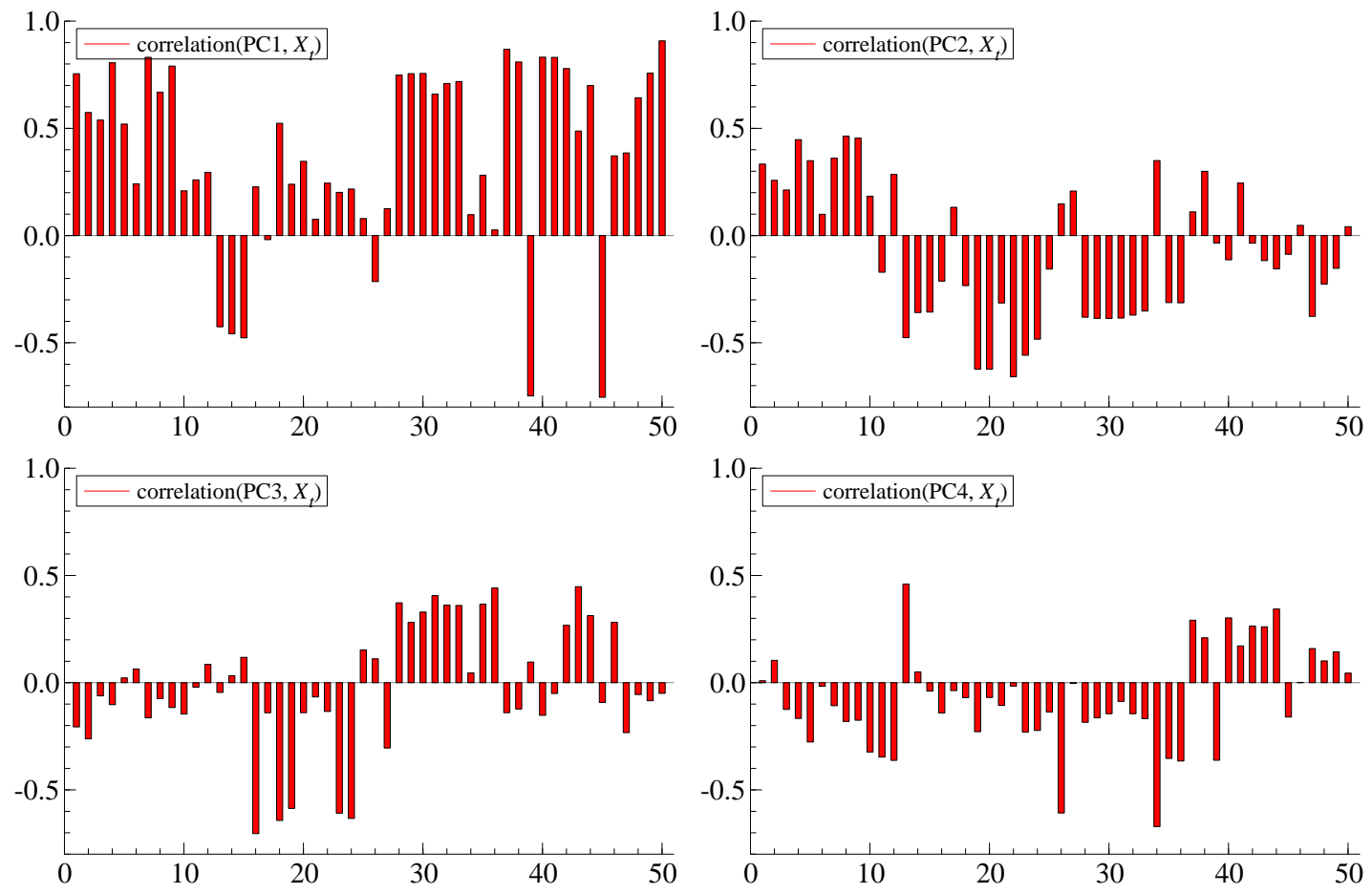

Figure 3: Correlation principal components (PCs) with the set of candidate predictors (euro area) 
20 and 30 percent of the comovement in the set of candidate predictors. Moreover, the explanatory power increases only very slightly after the fourth principal component. Figure 3 shows the correlation of the first four estimated principal components with the matrix of candidate predictors for the euro area.The $x$-axis has the candidate variables corresponding to the numbers in Table IV in the Appendix and the $y$-axis has the correlations in percent. The first principal component is strongly correlated with a broad range of variables apart from prices, which is in accordance with the high eigenvalue. This indicates that the bulk of the covariance of the candidate predictors can be explained by the first factor. The second and third principal components are strongly correlated with price variables, such as HICP, commodity prices and oil price, whilst the fourth principal component is highly correlated with financial variables, such as interest rates and exchange rates.

The factor model of Bańbura and Rünstler (2011) also requires a choice on the number of principal components to extract from the disturbance matrix in equation (3), the so called "dynamic" factors $q$. We followed a similar procedure as in Bańbura and Rünstler (2011) by imposing the restrictions $r \leq 4$ and $q \leq r$. The second restriction is motivated by the finding of D'Agostino and Giannone (2012) who stated that restricting the number of dynamic factors to be equal or less than the number of static factors does not hurt predictive power. Moreover, we need to choose between the original Bańbura and Rünstler (2011) and the augmented version of the model. Table IX in the Appendix compares the forecast accuracy of the original Bańbura and Rünstler (2011) model with the augmented version. We conclude that the forecast accuracy increases when the augmented version of the Bańbura and Rünstler (2011) model is used, though the differences are usually quite small. In the Tables in the remainder of this paper we will show the forecast accuracy of the augmented Bańbura and Rünstler (2011) model.

\section{Empirical results}

\subsection{Forecast accuracy using the complete sample}

This subsection describes the forecast accuracy of the factor models versus the benchmark model. The benchmark model is an autoregression of order 2. The factor models are the principal component model of Stock and Watson (SW), the augmented dynamic factor model of Bańbura and Rünstler (BR) and the collapsed dynamic factor model (CFM). In our analysis, we analyze the forecast performance for the euro area (EA) and its five largest countries, i.e.: Germany (DE), France (FR), Italy (IT), Spain (ES) and the Netherlands (NL). We measure forecast accuracy as the mean squared forecast error (MSFE).

Table [I] presents the forecast performance of the three factor models and the benchmark model for our five countries and the euro area for the complete length of the sample (1992.I2012.IV). The underlying empirical analysis has been carried out on a monthly basis for eleven horizons. To keep the table parsimonious we only report the average forecast accuracy for the one and two quarter ahead forecast, the nowcast and the backcast ${ }^{9}$ Moreover, the presented MSFEs are averaged over model specifications with one to four factors. The rows labeled $\mathrm{AR}(2)$ report the MSFE of the benchmark model. For the three factor models, the entries refer to their MSFE relative to the benchmark model in order to improve comparability of the results across countries and horizons. Shaded areas indicate the model with the lowest MSFE for a particular forecast horizon and a particular country. Bold faced entries indicate

\footnotetext{
${ }^{9}$ The forecast for the months within the quarters are available from the authors upon request.
} 
Table II: Forecast accuracy dynamic factor models (MSFE), 1992.I-2012.IV

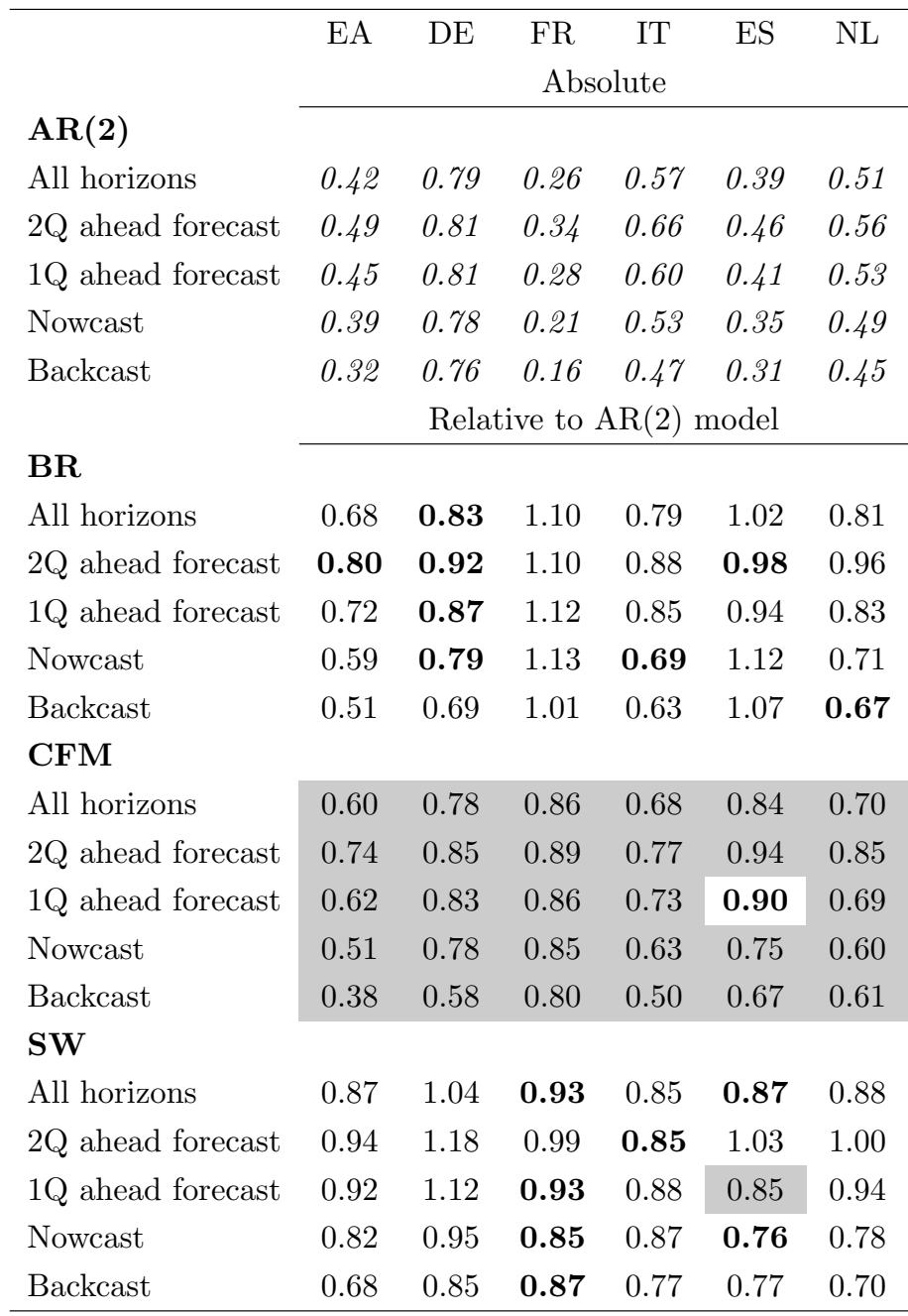

This table presents the MSFEs of backcasts, nowcasts, one quarter ahead forecasts and two quarter ahead forecasts as well as the average MSFE over all these horizons. The benchmark model is an autoregression of order $2(\mathrm{AR}(2))$. The factor models are: the principal component model with diffusion index of Stock and Watson (SW), the augmented dynamic factor model of Bańbura and Rünstler (BR) and the collapsed dynamic factor model (CFM). The country codes are: Euro Area (EA), Germany (DE), France (FR), Italy (IT), Spain (ES) and the Netherlands (NL). The model forecasts are averaged over model specifications with one to four factors. The smallest MSFE for each horizon is highlighted. MSFEs that are at most $10 \%$ larger than the MSFE of the best model and also smaller than the MSFE of the benchmark model are in boldface. 
models that have an MSFE that is less than 10\% larger than that of the best model and also smaller than the MSFE of the benchmark model. The $10 \%$ threshold is meant as a rough assessment of the economic significance of differences in forecasting ability. We will call models that meet this condition "competitive models" as in terms of forecast performance they do no differ "too much" from the best model 10 The outcomes in Table II point to several interesting results.

First, incorporating monthly information in a factor model pays off in terms of forecast accuracy, in particular for nowcasts and backcasts. Averaged over all horizons and countries, the improvement for the best models is around $26 \%$ on the benchmark AR(2) model, whilst the worst model still posts a gain of $9 \%$ on the benchmark. The results also indicate that predictions by the factor models deteriorate when the forecast horizon is longer. This is in line with previous research, that concludes that factor models are suitable for making nowcasts and backcasts but less suited for forecasting one and two quarters ahead, e.g. Giannone et al. (2008), Rünstler et al. (2009) and Bańbura and Rünstler (2011).

Second, the collapsed dynamic factor model displays the highest forecast accuracy. For most countries and horizons, the collapsed dynamic factor model performs the best. An exception is one quarter ahead forecast for Spain. However, in both cases the difference with the best model is negligible. The collapsed dynamic factor model posts the highest gains in forecast accuracy on the benchmark model for the euro area, ranging from an average improvement of $26 \%$ for the two quarter ahead forecast, to $62 \%$ for the backcasts.

Third, the collapsed dynamic factor model is the only model that beats the benchmark model by more than $10 \%$ or more across most countries and forecast horizons. The other two factor models have a less favorable forecast performance, i.e: the augmented Bańbura and Rünstler (2011) model fails to beat the benchmark model in France for all forecast horizons, whilst the Stock and Watson (2002) model is unable to outperform the benchmark model for Germany, Spain and the Netherlands when forecasting one or two quarters ahead.

These results provide the empirical evidence that predictions by dynamic factor models are especially well suited for nowcasting and backcasting. Also the results suggest that the collapsed dynamic factor model displays a significantly larger ability to absorb monthly information than the other two factor models we have considered in this study.

The relatively good forecast performance of the collapsed dynamic factor model is robust to model specification, as shown in Table $\mathrm{V}$ to VIII in the Appendix. The Tables show the forecast accuracy for model specifications with one to four factors respectively for all factor models.

\subsection{Forecasts for the Great Moderation and the Great Recession}

Our sample includes the period of the financial crisis. During this period we witness a sharp drop in a broad range of indicators, including manufacturing, confidence indicators and exports. As a consequence real GDP growth sharply drops across all industrialized countries. An interesting question is whether and to what extent the performance of the factor models differs between the volatile financial crisis and the years before which can be characterized as a relatively stable period. Forecasting in times of crisis poses greater challenges. Hence a comparative analysis that focusses on these periods may be even more informative on the issue which factor model is best suited to forecast GDP growth. To determine the influence of the financial crisis on the forecast accuracy of the factor models we divide the sample into

\footnotetext{
${ }^{10}$ We also conducted conventional statistical tests but -like other authors- we found these are not discriminating in practice. Details are available from the authors upon request.
} 
two periods; we take 1992.I-2007.IV and 2008.I-2012.IV. We refer to the latter period as the "Great Recession" and the former period as the "Great Recession". Table III presents the outcome of the forecast performance of the three factor models and the benchmark model for our five countries and the euro area during both periods. The comparison of these two distinct periods points to some interesting results that we describe next.

First, predicting GDP growth during the Great Recession is more difficult than during the Great Moderation. Depending on the country analyzed, the MSFE of the benchmark model during the Great Recession is two to six times larger than during the Great Moderation. This deterioration is partly offset as the scope for improving forecast by using monthly information appears to be larger during the Great Recession, in particular for nowcasting and backcasting. For example, the relative MSFE of the collapsed dynamic factor model improves by $51 \%$ during the Great Recession, compared to $14 \%$ during the Great Moderation. This finding is consistent with the results of D'Agostino and Giannone (2012) and Jansen et al. (2012). Both studies show that the gain in forecast accuracy is especially sizeable in periods of large swings and high comovement in the monthly predictors, as was the case during the Great Recession.

Second, when averaged over all horizons, the collapsed dynamic factor model is a highly competitive model during the Great Recession. This indicates that the model structure of the collapsed dynamic factor model is well suited to process monthly information in volatile times. This conclusion also holds for most countries when we analyze the forecast performance for each forecast horizon separately. The maximum gain in forecast accuracy against the benchmark model was $77 \%$, recorded for the backcasts in the euro area. However, there is one exception, i.e: in Spain the collapsed dynamic factor model is not competitive when nowcasting and forecasting one quarter ahead.

Third, during the Great Moderation the collapsed factor model is still the best model for most of the countries, but not for all countries. Averaged across forecast horizon the collapsed dynamic factor model is the best model for the euro area and three out of the five countries we analyzed (Germany, Italy, Spain), but for the Netherlands the forecast accuracy of the Bańbura and Rünstler (2011) is higher for all horizons, except for the one quarter ahead forecast. In France, none of the factor models is able to beat the benchmark model. Finally, the low forecast accuracy of the Stock and Watson (2002) model during the Great Moderation is somewhat surprising. The model is unable to improve upon the benchmark model for the majority of countries and forecast horizons.

Overall, splitting the total sample period into the volatile Great Recession and the more tranquil Great Moderation enhances the understanding of the forecast accuracy of factor models. We show that for the euro area and three of our five countries the collapsed dynamic factor model is the best forecasting model during the Great Moderation as well as during the Great Recession. However, for France and the Netherlands, the high forecast accuracy of the collapsed dynamic factor model is limited to the Great Recession. This finding underlines the importance of continuously monitoring the forecast accuracy of the short-term forecasting models that practitioners use on a routine basis.

\section{Conclusions}

This paper makes three contributions to the existing empirical literature on forecasting GDP in the short-term. The first contribution is empirical. We present the outcome of a forecasting study for two popular factor models amongst policy makers and the recently 
Table III: Forecast accuracy dynamic factor models (MSFE) during the Great Moderation and the Great Recession

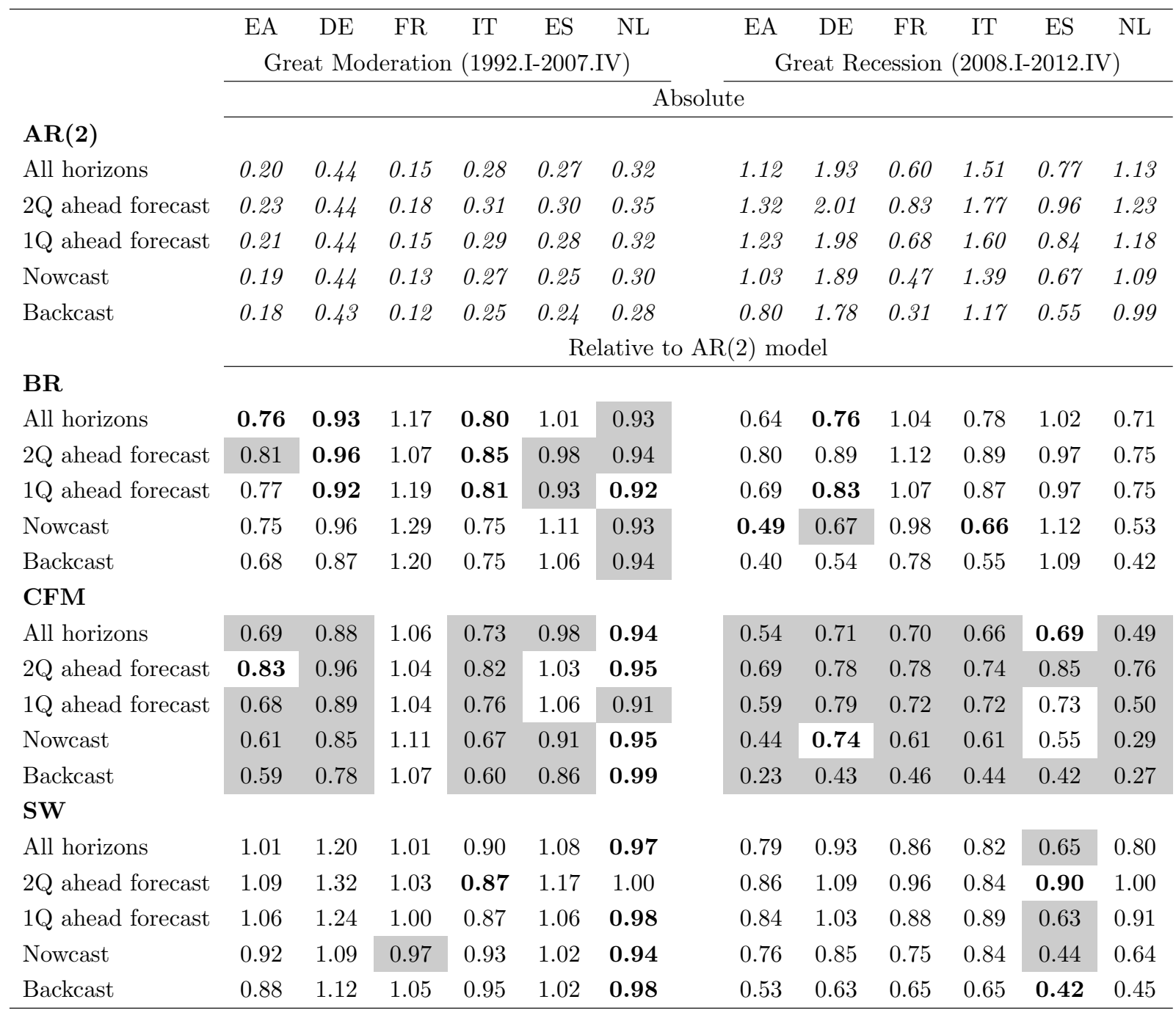

This table presents the MSFEs of backcasts, nowcasts, one quarter ahead forecasts and two quarter ahead forecasts as well as the average MSFE over all these horizons. The benchmark model is an autoregression of order $2(\operatorname{AR}(2))$. The factor models are: the principal component model with diffusion index of Stock and Watson (SW), the augmented dynamic factor model of Bańbura and Rünstler (BR) and the collapsed dynamic factor model (CFM). The country codes are: Euro Area (EA), Germany (DE), France (FR), Italy (IT), Spain (ES) and the Netherlands (NL). The model forecasts are averaged over model specifications with one to four factors. The smallest MSFE for each horizon is highlighted. MSFEs that are at most $10 \%$ larger than the MSFE of the best model and also smaller than the MSFE of the benchmark model are in boldface. 
developed collapsed dynamic factor model for the euro area and its five largest countries (Germany, France, Italy, Spain and the Netherlands) where we utilize the same information set for all countries and the euro area. Our sample (1992.I-2012.IV) allows us to discriminate between the performance of the factor models during the volatile financial crisis and the more tranquil years before the crisis. Our second and third contribution are extensions to the existing factor models. First, we extend the model of Bańbura and Rünstler (2011) by introducing an autoregressive term of the target variable (GDP). Second, we extend the collapsed dynamic factor by proposing an efficient way to deal with jagged edges at the beginning and end of the estimation period.

We summarize our findings in four points. First, factor models can extract valuable information for short-term GDP forecasting, in particular as the forecast horizon shortens and more monthly information is processed. We find the largest gains in forecast accuracy for nowcasting and backcasting, suggesting that factor models are especially helpful when they are able to use information that pertains to the quarter of interest.

Second, during the Great Recession the gains in forecast accuracy against a simple autoregressive benchmark model is more profound than during the Great Moderation. This finding underlines the importance of using factor models instead of simple benchmark models during volatile periods.

Third, in our study, the collapsed dynamic factor model has shown the highest forecast accuracy for the euro area and its five largest countries. For the euro area and three out of five countries (Germany, Italy and Spain) this result has been driven by the high forecast accuracy during the Great Recession as well as the Great Moderation. However, for France and the Netherlands the good performance of the collapsed dynamic factor model only applies to the Great Recession period.

Fourth, small changes in the structure of factor models can improve the forecast accuracy considerably. We show that the inclusion of an autoregressive term of the target variable GDP in the Bańbura and Rünstler (2011) model increases its forecast accuracy. Moreover, the careful and efficient handling of the jagged edges in the Bräuning and Koopman (2014) model is key to its good forecast performance.

The results of our large-scale comparative forecast analysis may be useful to econometricians and policy makers who regularly use short-term forecasting models. An interesting topic for future research is how to trace back the contribution of the monthly indicators to the GDP forecast of the collapsed dynamic factor model. The competing Bańbura and Rünstler (2011) model does have this feature, and the collapsed dynamic factor model would probably gain in its attractiveness for policy makers if this feature was incorporated as well.

\section{Acknowledgments}

The opinions expressed in this paper are personal views of the authors and do not necessarily reflect positions of De Nederlandsche Bank. We are grateful to seminar and conference participants at De Nederlandsche Bank and the Computational and Financial Econometrics Conference 2012 in Oviedo for their helpful comments. We are particularly indebted to Job Swank for his valuable comments and stimulating suggestions. SJK acknowledges support from CREATES, Center for Research in Econometric Analysis of Time Series (DNRF78), funded by the Danish National Research Foundation. 


\section{References}

Angelini, E., G. Camba-Mendez, D. Giannone, L. Reichlin, and G. Rnstler (2011). Shortterm forecasts of euro area GDP growth. Econometrics Journal 14(1), 25-44.

Bai, J. and S. Ng (2002). Determining the number of factors in approximate factor models. Econometrica $70(1), 191-221$.

Bai, J. and S. Ng (2007). Determining the number of primitive shocks in factor models. Journal of Business \& Economic Statistics 25(1), 52-60.

Bai, J. and S. Ng (2008). Large dimensional factor analyis. Foundations and Trends in Econometrics 3(2), 89-163.

Bańbura, M. and G. Rünstler (2011). A look into the factor model black box: publication lags and the role of hard and soft data in forecasting GDP. International Journal of Forecasting 27(2), 333-346.

Bernanke, B. S. and J. Boivin (2003). Monetary policy in a data-rich environment. Journal of Monetary Economics 50(3), 525-546.

Boivin, J. and S. Ng (2005). Understanding and comparing factor-based forecasts. International Journal of Central Banking 1(3), 117-151.

Bräuning, F. and S. J. Koopman (2014). Forecasting macroeconomic variables using collapsed dynamic factor analysis. International Journal of Forecasting 30(3), 572-584.

Breitung, J. and S. Eickmeier (2006). Dynamic factor models. AStA Advances in Statistical Analysis 90(1), 27-42.

Caggiano, G., G. Kapetanios, and V. Labhard (2011). Are more data always better for factor analysis? results for the euro area, the six largest euro area countries and the UK. Journal of Forecasting 30(8), 736-752.

Cattell, R. B. (1966). The scree test for the number of factors. Multivariate Behavioral Research 1(2), 245-276.

Clements, M. P. and A. B. Galvão (2008). Macroeconomic forecasting with mixed-frequency data: forecasting output growth in the United States. Journal of Business 83 Economic Statistics 26(4), 546-554.

D‘Agostino, A. and D. Giannone (2012). Comparing alternative predictors based on largepanel factor models. Oxford Bulletin of Economics and Statistics 74 (2), 306-326.

den Reijer, A. (2013). Forecasting Dutch GDP and inflation using alternative factor model specifications based on large and small datasets. Empirical Economics 44(2), 435-453.

Doz, C., D. Giannone, and L. Reichlin (2011). A two-step estimator for large approximate dynamic factor models based on Kalman filtering. Journal of Econometrics 164(1), 188205.

Durbin, J. and S. J. Koopman (2012). Time series analysis by state space methods. Oxford University Press. 
Giannone, D., L. Reichlin, and L. Sala (2005). Monetary policy in real time. In NBER Macroeconomics Annual 2004, Volume 19, pp. 161-224. National Bureau of Economic Research.

Giannone, D., L. Reichlin, and D. Small (2008). Nowcasting: the real-time informational content of macroeconomic data. Journal of Monetary Economics 55(4), 665-676.

Jansen, W. J., X. Jin, and J. M. de Winter (2012). Forecasting and nowcasting real GDP: comparing statistical models and subjective forecasts. DNB Working Papers 365, Netherlands Central Bank, Research Department.

Koopman, S. J. and A. Harvey (2003). Computing observation weights for signal extraction and filtering. Journal of Economic Dynamics and Control 27(7), 1317-1333.

Kuzin, V., M. Marcellino, and C. Schumacher (2011). MIDAS vs. mixed-frequency VAR: nowcasting GDP in the euro area. International Journal of Forecasting 27(2), 529-542.

Kuzin, V., M. Marcellino, and C. Schumacher (2013). Pooling versus model selection for nowcasting GDP with many predictors: empirical evidence for six industrialized countries. Journal of Applied Econometrics 28(3), 392-411.

Mariano, R. S. and Y. Murasawa (2003). A new coincident index of business cycles based on monthly and quarterly series. Journal of Applied Econometrics 18(4), 427-443.

Rünstler, G., K. Barhoumi, S. Benk, R. Cristadoro, A. den Reijer, A. Jakaitiene, P. Jelonek, A. Rua, K. Ruth, and C. V. Nieuwenhuyze (2009). Short-term forecasting of GDP using large datasets: a pseudo real-time forecast evaluation exercise. Journal of Forecasting 28(7), 595-611.

Schumacher, C. and J. Breitung (2008). Real-time forecasting of German GDP based on a large factor model with monthly and quarterly data. International Journal of Forecasting $24(3), 386-398$.

Stock, J. H. and M. W. Watson (2002). Macroeconomic forecasting using diffusion indexes. Journal of Business \& Economic Statistics 20(2), 147-162.

Stock, J. H. and M. W. Watson (2006). Why has U.S. inflation become harder to forecast? NBER Working Papers 12324, National Bureau of Economic Research. 


\section{A Appendix}

\section{A.1 Dataset}

Table IV: Monthly series in uniform dataset

\begin{tabular}{|c|c|c|c|c|c|c|c|c|c|c|}
\hline \multirow[t]{2}{*}{ Nr. } & \multirow[t]{2}{*}{ Variable } & \multicolumn{3}{|c|}{ Transformation } & \multicolumn{6}{|c|}{ Country } \\
\hline & & sa & $\ln$. & dif. & EA & $\mathrm{DE}$ & FR & IT & ES & NL \\
\hline \multicolumn{11}{|c|}{ I. Production \& sales $(\mathrm{N}=15)$} \\
\hline 1 & World Trade & 1 & 1 & 1 & '77 & '77 & '77 & '77 & '77 & '77 \\
\hline 2 & Ind. prod. US & 1 & 1 & 1 & ‘60 & ‘60 & '60 & ‘ 60 & ‘60 & ‘60 \\
\hline 3 & Ind. prod. UK & 1 & 1 & 1 & '68 & '68 & ' 68 & ‘ 68 & ' 68 & '68 \\
\hline 4 & Ind. prod. (excl. constr.) & 1 & 1 & 1 & ‘60 & '60 & ' 60 & ‘60 & ‘ 61 & ‘ 62 \\
\hline 5 & Ind. prod., consumer goods & 2 & 1 & 1 & ' 80 & ' 80 & '63 & ‘60 & ‘65 & ‘90 \\
\hline 6 & Ind. prod., energy & 2 & 1 & 1 & ‘80 & '91 & ' 63 & ' 80 & ‘ 80 & '00 \\
\hline 7 & Ind. prod., interm. goods & 1 & 1 & 1 & ‘60 & ‘ 80 & '63 & ' 77 & '65 & '00 \\
\hline 8 & Ind. prod., capital goods & 1 & 1 & 1 & ‘60 & '80 & ‘63 & '77 & 65 & ‘70 \\
\hline 9 & Ind. prod., manufacturing & 2 & 1 & 1 & ‘60 & ' 78 & ‘60 & '71 & 80 & '70 \\
\hline 10 & Ind. prod., construction & 2 & 1 & 1 & '85 & ' 78 & '85 & '95 & '88 & ‘ 85 \\
\hline 11 & Passenger car registration & 1 & 1 & 1 & ‘ 77 & ' 77 & '77 & '77 & '77 & '79 \\
\hline 12 & Retail trade volume & 2 & 1 & 1 & ‘ 70 & ' 68 & 70 & ' 90 & 95 & ‘60 \\
\hline 13 & Unemployment rate & 1 & 0 & 1 & ' 83 & ‘62 & '83 & ‘ 83 & ' 86 & ‘ 83 \\
\hline 14 & Unemployment rate UK & 1 & 0 & 1 & '83 & ' 83 & '83 & ‘ 83 & '83 & ‘ 83 \\
\hline 15 & Unemployment rate US & 1 & 0 & 1 & '83 & ' 83 & '83 & ‘ 83 & '83 & ‘ 83 \\
\hline \multicolumn{11}{|c|}{ II. Prices $(\mathrm{N}=9)$} \\
\hline 16 & Total HICP-index & 2 & 1 & 2 & ‘60 & ‘60 & '60 & ' 60 & '60 & ' 60 \\
\hline 17 & Core HICP-index & 2 & 1 & 2 & ‘ 62 & '62 & 60 & 60 & '76 & 61 \\
\hline 18 & Producer prices & 2 & 1 & 2 & '81 & ‘60 & '62 & '70 & 60 & 60 \\
\hline 19 & Commod. prices, tot. & 2 & 1 & 2 & ‘60 & ‘60 & ‘60 & ‘60 & 60 & ‘60 \\
\hline 20 & Commod. prices, ind. mat. & 2 & 1 & 2 & ‘60 & ' 60 & '60 & ‘ 60 & ‘60 & ‘ 60 \\
\hline 21 & Commod. prices, food-bev. & 2 & 1 & 2 & ‘ 60 & ‘ 60 & '60 & ‘60 & ' 60 & ' 60 \\
\hline 22 & Commod. prices, metals & 2 & 1 & 2 & ‘60 & ‘60 & ‘60 & ‘60 & 60 & ‘ 60 \\
\hline 23 & Commod. prices, energy & 2 & 1 & 2 & ‘60 & ‘60 & ‘60 & ‘60 & ‘60 & ‘60 \\
\hline 24 & Oil price & 2 & 1 & 2 & ‘85 & '85 & '85 & '85 & '85 & '85 \\
\hline \multicolumn{11}{|c|}{ III. Monetary \& financial indicators $(\mathrm{N}=14)$} \\
\hline 25 & M1 & 2 & 1 & 1 & '70 & ' 80 & ' 80 & ‘ 80 & ' 80 & ' 80 \\
\hline 26 & M3 & 2 & 1 & 1 & '70 & '70 & '70 & ‘70 & '70 & ‘70 \\
\hline 27 & Int. rate mortgage & 2 & 0 & 1 & '03 & ' 82 & ' 80 & '95 & ' 84 & ‘ 80 \\
\hline 28 & 3 month interest rate & 2 & 0 & 1 & '94 & ' 60 & '64 & ‘60 & ‘ 60 & ‘ 60 \\
\hline 29 & 10 year gov. bond yield & 2 & 0 & 1 & '70 & ‘60 & 70 & ‘60 & '80 & ‘60 \\
\hline 30 & Headline stock-index & 2 & 1 & 1 & ' 73 & '73 & 73 & ' 73 & '87 & ' 73 \\
\hline 31 & Basic material-index & 2 & 1 & 1 & ' 73 & ' 73 & '73 & ' 73 & ' 87 & ' 73 \\
\hline 32 & Industrials stock-index & 2 & 1 & 1 & ' 73 & ' 73 & $' 73$ & '73 & ' 87 & ' 73 \\
\hline 33 & Cons. goods stock-index & 2 & 1 & 1 & ' 73 & ' 73 & '73 & '73 & ' 87 & '73 \\
\hline 34 & Cons. service stock-index & 2 & 1 & 1 & '73 & '73 & 73 & ' 73 & ' 87 & ' 73 \\
\hline 35 & Financials stock-index & 2 & 1 & 1 & ' 73 & ' 73 & '73 & '73 & ' 87 & ' 73 \\
\hline 36 & Loans to the private sector & 2 & 1 & 1 & ‘ 80 & ‘ 80 & '80 & '83 & ' 80 & ' 82 \\
\hline 37 & Exchange rate, $\$$ per EUR & 2 & 1 & 1 & ' 74 & '74 & '74 & '74 & '74 & '74 \\
\hline 38 & Real eff. exchange rate & 2 & 1 & 1 & '70 & '70 & '70 & ' 70 & '70 & ' 70 \\
\hline \multicolumn{11}{|c|}{ IV. Surveys $(N=14)$} \\
\hline 39 & Ind. conf. - headline & 1 & 0 & 1 & ‘ 85 & ' 85 & ' 85 & '85 & ' 87 & '85 \\
\hline 40 & Ind. conf. - orders & 1 & 0 & 1 & '85 & '85 & '85 & '85 & ' 87 & '85 \\
\hline
\end{tabular}

Continued on next page 
Table IV - Continued from previous page

\begin{tabular}{|c|c|c|c|c|c|c|c|c|c|c|}
\hline \multirow[t]{2}{*}{ Nr. } & \multirow[t]{2}{*}{ Variable } & \multicolumn{3}{|c|}{ Transformation } & \multicolumn{6}{|c|}{ Country } \\
\hline & & sa & $\ln$. & dif. & EA & $\mathrm{DE}$ & FR & IT & ES & NL \\
\hline 41 & Ind. conf. - stocks & 1 & 0 & 1 & '85 & '85 & 85 & '85 & 87 & '85 \\
\hline 42 & Ind. conf. - prod. expect. & 1 & 0 & 1 & ‘85 & '85 & '85 & '85 & ‘87 & ‘ 85 \\
\hline 43 & Ind. conf. - empl. expect. & 1 & 0 & 1 & ' 85 & '85 & ' 85 & ' 85 & ' 87 & ' 85 \\
\hline 44 & Cons. conf. - headline & 1 & 0 & 1 & '85 & '85 & ‘85 & '85 & ' 86 & ‘ 85 \\
\hline 45 & Cons. conf. - exp. fin. sit. & 1 & 0 & 1 & '85 & '85 & '85 & ‘ 85 & ‘ 86 & ‘ 85 \\
\hline 46 & Cons. conf. - exp. ec. sit. & 1 & 0 & 1 & '85 & ‘85 & ' 85 & ‘85 & '86 & ‘ 85 \\
\hline 47 & Cons. conf. - exp. unemp. & 1 & 0 & 1 & ' 85 & '85 & '85 & ' 85 & '86 & '85 \\
\hline 48 & Cons. conf. - exp. maj. pur. & 1 & 0 & 1 & '85 & ‘85 & '85 & ‘85 & '86 & ‘85 \\
\hline 49 & PMI United States & 1 & 0 & 1 & ‘60 & ‘60 & ‘60 & ' 60 & ' 60 & ‘ 60 \\
\hline 50 & OECD leading ind. UK & 1 & 1 & 1 & ' 60 & '60 & ‘60 & ' 60 & 60 & ‘ 60 \\
\hline 51 & OECD leading ind. US & 1 & 1 & 1 & '60 & ‘60 & ‘60 & ‘60 & ' 60 & ‘60 \\
\hline 52 & OECD comp. leading ind. & 1 & 1 & 1 & ‘ 70 & ' 61 & ‘70 & '62 & ' 76 & ‘61 \\
\hline
\end{tabular}

This table presents the starting year of the monthly series that were used for estimation. Series for which the time series starts later than 1986 are highlighted and excluded in the models because the series are too short. transform: sa: $1=$ seasonal adjustment at the source, $2=$ seasonal adjustment by US Census X12-method, log: $0=$ no logarithm, $1=\log$ arithm, dif.: degree of differencing $1=$ first difference, $2=$ second difference 


\section{A.2 Number of factors in dynamic factor models}

Table V: Forecast accuracy dynamic factor models (MSFE), 1992.I-2012.IV, one factor

\begin{tabular}{|c|c|c|c|c|c|c|}
\hline & EA & $\mathrm{DE}$ & FR & IT & ES & NL \\
\hline & \multicolumn{6}{|c|}{ Absolute } \\
\hline \multicolumn{7}{|l|}{$\mathbf{A R}$} \\
\hline All horizons & 0.42 & 0.79 & 0.26 & 0.57 & 0.39 & 0.51 \\
\hline 2Q ahead forecast & 0.49 & 0.81 & 0.34 & 0.66 & 0.46 & 0.56 \\
\hline 1Q ahead forecast & 0.45 & 0.81 & 0.28 & 0.60 & 0.41 & 0.53 \\
\hline Nowcast & 0.39 & 0.78 & 0.21 & 0.53 & 0.35 & 0.49 \\
\hline \multirow[t]{2}{*}{ Backcast } & 0.32 & 0.76 & 0.16 & 0.47 & 0.31 & 0.45 \\
\hline & \multicolumn{6}{|c|}{ Relative to $\operatorname{AR}(2)$ model } \\
\hline \multicolumn{7}{|l|}{ BR } \\
\hline All horizons & 0.73 & 0.80 & 1.18 & 0.81 & 1.04 & 0.85 \\
\hline 2Q ahead forecast & 0.83 & 0.94 & 1.15 & 0.88 & 1.05 & 0.99 \\
\hline 1Q ahead forecast & 0.78 & 0.86 & 1.21 & 0.87 & 1.03 & 0.87 \\
\hline Nowcast & 0.64 & 0.70 & 1.24 & 0.75 & 1.11 & 0.77 \\
\hline Backcast & 0.58 & 0.63 & 1.07 & 0.67 & 0.94 & 0.71 \\
\hline \multicolumn{7}{|l|}{ CFM } \\
\hline All horizons & 0.64 & 0.73 & 0.95 & 0.73 & 0.91 & 0.72 \\
\hline $2 \mathrm{Q}$ ahead forecast & 0.79 & 0.87 & 0.95 & 0.83 & 0.95 & 0.84 \\
\hline 1Q ahead forecast & 0.65 & 0.76 & 0.92 & 0.77 & 0.92 & 0.71 \\
\hline Nowcast & 0.52 & 0.63 & 0.98 & 0.64 & 0.88 & 0.63 \\
\hline Backcast & 0.49 & 0.57 & 0.97 & 0.58 & 0.87 & 0.65 \\
\hline \multicolumn{7}{|l|}{ SW } \\
\hline All horizons & 0.83 & 1.00 & 0.88 & 0.86 & 0.86 & 0.86 \\
\hline $2 \mathrm{Q}$ ahead forecast & 0.89 & 1.12 & 0.98 & 0.88 & 0.98 & 0.96 \\
\hline $1 \mathrm{Q}$ ahead forecast & 0.88 & 1.08 & 0.88 & 0.90 & 0.87 & 0.90 \\
\hline Nowcast & 0.78 & 0.92 & 0.78 & 0.87 & 0.73 & 0.79 \\
\hline Backcast & 0.64 & 0.79 & 0.77 & 0.72 & 0.83 & 0.74 \\
\hline
\end{tabular}

This table presents the MSFEs of backcasts, nowcasts, one and two quarter ahead forecasts. The benchmark model is an autoregression of order $2(\operatorname{AR}(2))$. The factor models are: the principal component of Stock and Watson model (SW), the augmented dynamic factor model of Bańbura and Rünstler (BR) and the collapsed dynamic factor model (CFM). The country codes are: Euro Area (EA), Germany (DE), France (FR), Italy (IT), Spain (ES) and the Netherlands (NL). The model forecasts are averaged over model specifications with one to four factors. The smallest MSFE for each horizon is highlighted. MSFEs that are at most $10 \%$ larger than the MSFE of the best model and also smaller than the MSFE of the benchmark model are in boldface. 
Table VI: Forecast accuracy dynamic factor models (MSFE), 1992.I-2012.IV, two factors

\begin{tabular}{|c|c|c|c|c|c|c|}
\hline & EA & $\mathrm{DE}$ & FR & IT & $\mathrm{ES}$ & NL \\
\hline & \multicolumn{6}{|c|}{ Absolute } \\
\hline \multicolumn{7}{|l|}{ AR } \\
\hline All horizons & 0.42 & 0.79 & 0.26 & 0.57 & 0.39 & 0.51 \\
\hline 2Q ahead forecast & 0.49 & 0.81 & 0.34 & 0.66 & 0.46 & 0.56 \\
\hline 1Q ahead forecast & 0.45 & 0.81 & 0.28 & 0.60 & 0.41 & 0.53 \\
\hline Nowcast & 0.39 & 0.78 & 0.21 & 0.53 & 0.35 & 0.49 \\
\hline \multirow[t]{2}{*}{ Backcast } & 0.32 & 0.76 & 0.16 & 0.47 & 0.31 & 0.45 \\
\hline & \multicolumn{6}{|c|}{ Relative to $\mathrm{AR}(2)$ model } \\
\hline \multicolumn{7}{|l|}{ BR } \\
\hline All horizons & 0.73 & 0.97 & 1.26 & 0.76 & 1.03 & 0.72 \\
\hline $2 \mathrm{Q}$ ahead forecast & 0.81 & 1.03 & 1.12 & 0.87 & 1.01 & 0.88 \\
\hline $1 \mathrm{Q}$ ahead forecast & 0.74 & 0.97 & 1.21 & 0.81 & 0.99 & 0.70 \\
\hline Nowcast & 0.66 & 1.01 & 1.48 & 0.64 & 1.12 & 0.61 \\
\hline Backcast & 0.66 & 0.79 & 1.41 & 0.66 & 1.03 & 0.63 \\
\hline \multicolumn{7}{|l|}{ CFM } \\
\hline All horizons & 0.58 & 0.85 & 0.91 & 0.66 & 0.89 & 0.74 \\
\hline $2 \mathrm{Q}$ ahead forecast & 0.69 & 0.84 & 0.94 & 0.74 & 0.91 & 0.88 \\
\hline $1 \mathrm{Q}$ ahead forecast & 0.57 & 0.85 & 0.91 & 0.68 & 0.90 & 0.72 \\
\hline Nowcast & 0.50 & 0.91 & 0.90 & 0.57 & 0.86 & 0.65 \\
\hline Backcast & 0.49 & 0.76 & 0.86 & 0.59 & 0.84 & 0.65 \\
\hline \multicolumn{7}{|l|}{ SW } \\
\hline All horizons & 0.87 & 1.05 & 0.91 & 0.90 & 0.91 & 0.93 \\
\hline $2 \mathrm{Q}$ ahead forecast & 0.91 & 1.16 & 0.98 & 0.91 & 1.04 & 1.05 \\
\hline 1Q ahead forecast & 0.92 & 1.14 & 0.91 & 0.91 & 0.87 & 1.01 \\
\hline Nowcast & 0.84 & 0.97 & 0.83 & 0.93 & 0.79 & 0.82 \\
\hline Backcast & 0.73 & 0.85 & 0.87 & 0.80 & 0.90 & 0.73 \\
\hline
\end{tabular}

This table presents the MSFEs of backcasts, nowcasts, one and two quarter ahead forecasts. The benchmark model is an autoregression of order $2(\mathrm{AR}(2))$. The factor models are: the principal component of Stock and Watson model (SW), the augmented dynamic factor model of Bańbura and Rünstler (BR) and the collapsed dynamic factor model (CFM). The country codes are: Euro Area (EA), Germany (DE), France (FR), Italy (IT), Spain (ES) and the Netherlands (NL). The model forecasts are averaged over model specifications with one to four factors. The smallest MSFE for each horizon is highlighted. MSFEs that are at most $10 \%$ larger than the MSFE of the best model and also smaller than the MSFE of the benchmark model are in boldface. 
Table VII: Forecast accuracy dynamic factor models (MSFE), 1992.I-2012.IV, three factors

\begin{tabular}{|c|c|c|c|c|c|c|}
\hline & EA & $\mathrm{DE}$ & FR & $\mathrm{IT}$ & $\mathrm{ES}$ & NL \\
\hline & \multicolumn{6}{|c|}{ Absolute } \\
\hline \multicolumn{7}{|l|}{$\mathbf{A R}$} \\
\hline All horizons & $0.4^{2}$ & 0.79 & 0.26 & 0.57 & 0.39 & 0.51 \\
\hline $2 \mathrm{Q}$ ahead forecast & 0.49 & 0.81 & 0.34 & 0.66 & 0.46 & 0.56 \\
\hline $1 \mathrm{Q}$ ahead forecast & 0.45 & 0.81 & 0.28 & 0.60 & 0.41 & 0.53 \\
\hline Nowcast & 0.39 & 0.78 & 0.21 & 0.53 & 0.35 & 0.49 \\
\hline \multirow[t]{2}{*}{ Backcast } & 0.32 & 0.76 & 0.16 & 0.47 & 0.31 & 0.45 \\
\hline & \multicolumn{6}{|c|}{ Relative to $\mathrm{AR}(2)$ model } \\
\hline \multicolumn{7}{|l|}{ BR } \\
\hline All horizons & 0.75 & 0.85 & 1.21 & 0.78 & 0.92 & 0.75 \\
\hline $2 \mathrm{Q}$ ahead forecast & 0.80 & 0.94 & 1.12 & 0.87 & 0.98 & 0.91 \\
\hline $1 \mathrm{Q}$ ahead forecast & 0.76 & 0.88 & 1.16 & 0.83 & 0.85 & 0.75 \\
\hline Nowcast & 0.75 & 0.86 & 1.36 & 0.72 & 0.93 & 0.62 \\
\hline Backcast & 0.65 & 0.67 & 1.3 & 0.63 & 0.89 & 0.63 \\
\hline \multicolumn{7}{|l|}{ CFM } \\
\hline All horizons & 0.64 & 0.87 & 0.94 & 0.71 & 0.92 & 0.72 \\
\hline $2 \mathrm{Q}$ ahead forecast & 0.73 & 0.92 & 0.98 & 0.74 & 0.97 & 0.89 \\
\hline $1 \mathrm{Q}$ ahead forecast & 0.66 & 0.92 & 0.94 & 0.74 & 0.97 & 0.70 \\
\hline Nowcast & 0.59 & 0.90 & 0.91 & 0.72 & 0.85 & 0.60 \\
\hline Backcast & 0.48 & 0.68 & 0.86 & 0.56 & 0.82 & 0.64 \\
\hline \multicolumn{7}{|l|}{ SW } \\
\hline All horizons & 0.87 & 1.11 & 0.91 & 0.89 & 0.99 & 0.99 \\
\hline $2 \mathrm{Q}$ ahead forecast & 0.94 & 1.27 & 0.95 & 0.88 & 1.13 & 1.09 \\
\hline 1Q ahead forecast & 0.91 & 1.19 & 0.92 & 0.92 & 0.97 & 1.05 \\
\hline Nowcast & 0.83 & 0.99 & 0.86 & 0.9 & 0.88 & 0.93 \\
\hline Backcast & 0.72 & 0.92 & 0.88 & 0.81 & 0.90 & 0.81 \\
\hline
\end{tabular}

This table presents the MSFEs of backcasts, nowcasts, one and two quarter ahead forecasts. The benchmark model is an autoregression of order $2(\mathrm{AR}(2))$. The factor models are: the principal component of Stock and Watson model (SW), the augmented dynamic factor model of Bańbura and Rünstler (BR) and the collapsed dynamic factor model (CFM). The country codes are: Euro Area (EA), Germany (DE), France (FR), Italy (IT), Spain (ES) and the Netherlands (NL). The model forecasts are averaged over model specifications with one to four factors. The smallest MSFE for each horizon is highlighted. MSFEs that are at most $10 \%$ larger than the MSFE of the best model and also smaller than the MSFE of the benchmark model are in boldface. 
Table VIII: Forecast accuracy dynamic factor models (MSFE), 1992.I-2012.IV, four factors

\begin{tabular}{|c|c|c|c|c|c|c|}
\hline & EA & $\mathrm{DE}$ & FR & $\mathrm{IT}$ & $\mathrm{ES}$ & NL \\
\hline & \multicolumn{6}{|c|}{ Absolute } \\
\hline \multicolumn{7}{|l|}{$\mathbf{A R}$} \\
\hline All horizons & $0.4^{2}$ & 0.79 & 0.26 & 0.57 & 0.39 & 0.51 \\
\hline 2Q ahead forecast & 0.49 & 0.81 & 0.34 & 0.66 & 0.46 & 0.56 \\
\hline $1 \mathrm{Q}$ ahead forecast & 0.45 & 0.81 & 0.28 & 0.60 & 0.41 & 0.53 \\
\hline Nowcast & 0.39 & 0.78 & 0.21 & 0.53 & 0.35 & 0.49 \\
\hline \multirow[t]{2}{*}{ Backcast } & 0.32 & 0.76 & 0.16 & 0.47 & 0.31 & 0.45 \\
\hline & \multicolumn{6}{|c|}{ Relative to $\mathrm{AR}(2)$ model } \\
\hline \multicolumn{7}{|l|}{ BR } \\
\hline All horizons & 0.75 & 0.83 & 1.21 & 0.76 & 0.88 & 0.78 \\
\hline $2 \mathrm{Q}$ ahead forecast & 0.81 & 0.92 & 1.10 & 0.87 & 0.99 & 0.95 \\
\hline $1 \mathrm{Q}$ ahead forecast & 0.73 & 0.87 & 1.14 & 0.85 & 0.85 & 0.78 \\
\hline Nowcast & 0.75 & 0.84 & 1.42 & 0.68 & 0.83 & 0.64 \\
\hline Backcast & 0.65 & 0.62 & 1.35 & 0.52 & 0.77 & 0.66 \\
\hline \multicolumn{7}{|l|}{ CFM } \\
\hline All horizons & 0.67 & 0.86 & 0.80 & 0.75 & 0.93 & 0.71 \\
\hline $2 \mathrm{Q}$ ahead forecast & 0.79 & 0.86 & 0.82 & 0.81 & 1.10 & 0.87 \\
\hline $1 \mathrm{Q}$ ahead forecast & 0.69 & 0.92 & 0.80 & 0.80 & 0.99 & 0.68 \\
\hline Nowcast & 0.62 & 0.95 & 0.78 & 0.75 & 0.75 & 0.61 \\
\hline Backcast & 0.43 & 0.65 & 0.77 & 0.53 & 0.73 & 0.61 \\
\hline \multicolumn{7}{|l|}{ SW } \\
\hline All horizons & 1.01 & 1.15 & 1.12 & 0.87 & 0.97 & 0.99 \\
\hline $2 \mathrm{Q}$ ahead forecast & 1.13 & 1.33 & 1.13 & 0.86 & 1.18 & 1.12 \\
\hline 1Q ahead forecast & 1.08 & 1.17 & 1.13 & 0.87 & 0.90 & 1.06 \\
\hline Nowcast & 0.95 & 1.04 & 1.12 & 0.90 & 0.84 & 0.88 \\
\hline Backcast & 0.73 & 0.98 & 1.10 & 0.84 & 0.86 & 0.80 \\
\hline
\end{tabular}

This table presents the MSFEs of backcasts, nowcasts, one and two quarter ahead forecasts. The benchmark model is an autoregression of order $2(\mathrm{AR}(2))$. The factor models are: the principal component of Stock and Watson model (SW), the augmented dynamic factor model of Bańbura and Rünstler (BR) and the collapsed dynamic factor model (CFM). The country codes are: Euro Area (EA), Germany (DE), France (FR), Italy (IT), Spain (ES) and the Netherlands (NL). The model forecasts are averaged over model specifications with one to four factors. The smallest MSFE for each horizon is highlighted. MSFEs that are at most $10 \%$ larger than the MSFE of the best model and also smaller than the MSFE of the benchmark model are in boldface. 


\section{A.3 Adding an AR(2) term in Bańbura and Rünstler (2011)}

Table IX: Sensitivity analysis (augmented) Bańbura and Rünstler model

\begin{tabular}{lccccccc}
\hline & EA & DE & FR & IT & ES & NL \\
& \multicolumn{6}{c}{ Absolute MSFE } \\
\cline { 2 - 7 } Base BR model \\
\cline { 2 - 7 } 1 factor & 0.56 & $\mathbf{0 . 8 0}$ & 0.61 & $\mathbf{0 . 6 9}$ & $\mathbf{0 . 6 7}$ & $\mathbf{0 . 6 6}$ \\
2 factor & $\mathbf{0 . 5 7}$ & $\mathbf{0 . 9 1}$ & $\mathbf{0 . 6 0}$ & 0.66 & $\mathbf{0 . 6 6}$ & $\mathbf{0 . 6 1}$ \\
3 factor & $\mathbf{0 . 5 7}$ & $\mathbf{0 . 8 6}$ & $\mathbf{0 . 5 8}$ & 0.67 & $\mathbf{0 . 6 1}$ & $\mathbf{0 . 6 3}$ \\
4 factor & $\mathbf{0 . 5 8}$ & $\mathbf{0 . 8 4}$ & $\mathbf{0 . 5 8}$ & 0.66 & $\mathbf{0 . 6 0}$ & $\mathbf{0 . 6 3}$ \\
average 1-4 factors & $\mathbf{0 . 5 5}$ & $\mathbf{0 . 8 2}$ & $\mathbf{0 . 5 8}$ & 0.65 & $\mathbf{0 . 6 2}$ & $\mathbf{0 . 6 3}$
\end{tabular}

Augmented BR model

\begin{tabular}{lllllll}
1 factor & $\mathbf{0 . 5 6}$ & 0.80 & 0.55 & 0.68 & 0.64 & 0.66 \\
2 factor & 0.56 & 0.88 & 0.57 & $\mathbf{0 . 6 6}$ & 0.63 & 0.61 \\
3 factor & 0.56 & 0.82 & 0.55 & $\mathbf{0 . 6 7}$ & 0.60 & 0.62 \\
4 factor & 0.56 & 0.81 & 0.56 & $\mathbf{0 . 6 6}$ & 0.58 & 0.63 \\
average 1-4 factors & 0.54 & 0.80 & 0.55 & $\mathbf{0 . 6 5}$ & 0.60 & 0.62 \\
\hline
\end{tabular}

This table presents the average MSFE over all forecast horizons (backcast, nowcast, one quarter ahead forecast and two quarter ahead forecast) for the Bańbura and Rünstler (2011) model and the augmented Bańbura and Rünstler (2011] model. The country codes are: Euro Area (EA), Germany (DE), France (FR), Italy (IT), Spain (ES) and the Netherlands (NL). Forecasts for specification with four static factors. The smallest MSFE for each horizon is highlighted. MSFEs that are at most $10 \%$ larger than the MSFE of the best model are in boldface. 